\title{
The Effects of Efficiency and TFP Growth on Pollution in Europe: A Multistage Spatial Analysis
}

\author{
Morakinyo Adetutu*, Anthony J. Glass ${ }^{\dagger}$, Karligash Kenjegalieva ${ }^{\ddagger}$ and \\ Robin C. Sickles $\$$
}

2014

\begin{abstract}
It is common in efficiency studies which analyse the environment for pollution to form part of the production technology. Pollution therefore affects efficiency and the TFP growth decomposition. As an alternative approach we draw on theoretical studies from the environmental economics literature, which demonstrate that TFP affects environmental quality. Along these lines we adopt a two-stage empirical methodology. Firstly, we obtain two estimates of productive performance (efficiency and TFP growth) using a stochastic production frontier framework in Stage 1 for European countries (1995 - 2008), from which we omit emissions. Secondly, in Stage 2 these measures of productive performance are used as regressors in spatial models of per capita nitrogen and sulphur emissions for European countries. From our preferred Stage 2 spatial models we find that a country's TFP growth must fall to reduce its per capita nitrogen and sulphur emissions. This is likely to be because nitrogen and sulphur emissions in the EU have been tightly regulated for a long period of time via air quality standards and consequently, substantial reductions in emissions from cleaner and more productive technology were achieved some time ago.
\end{abstract}

Keywords: TFP Growth; Atmospheric Pollution; Spatial Econometrics; Technical Efficiency

JEL Classification: C23; D24; Q53

${ }^{*}$ School of Business and Economics, Loughborough University, Leics, UK. Email: M.O.Adetutu@lboro.ac.uk.

${ }^{\dagger}$ School of Business and Economics, Loughborough University, Leics, UK. Email: A.J.Glass@lboro.ac.uk.

${ }^{\ddagger}$ School of Business and Economics, Loughborough University, Leics, UK. Email: K.A.Kenjegalieva@lboro.ac.uk.

$\S$ Corresponding author

`Department of Economics, Rice University, Houston, U.S. and School of Business and Economics, Loughborough University, Leics, UK. Email: rsickles@rice.edu 


\section{Introduction}

It is common practice in efficiency studies where there is a negative externality associated with production to jointly model the negative externality and the production of marketed output. By far and away the most popular approach to model such a situation is non-parametric (i.e. Data Envelopment Analysis, DEA) and involves using a multiple output-oriented specification of the production technology, where at least one output is undesirable. Studies which have adopted this approach where at least one pollutant is modelled as an undesirable output include Färe $e t$ al. (1989; 1996), Tyteca (1997), Hernandez-Sancho et al. (2000), Reinhard et al. (2000), Weber and Domazlicky (2001) and Zaim and Taskin (2000). Alternative approaches are parametric (i.e. Stochastic Frontier Analysis, SFA) and involve using either an input-oriented or multiple output-oriented approach. Studies which use the input-oriented approach and where pollution is the negative externality include Reinhard et al. (1999; 2000) and Atkinson and Dorfman (2005). Glass et al. (2013a) also use the input-oriented approach where urban highway congestion is the negative externality. ${ }^{1}$ There are two multiple output-oriented methods. The first involves using an inverse transformation of the undesirable output to obtain a good output and has been applied in the context of pollution by Fernández et al. (2005) and Koop and Tole (2008). The second is due to Cuesta et al. (2009) and is the parametric counterpart to studies such as Färe et al. (1989). With this method, a hyperbolic distance function is used where the outputs vector is treated asymmetrically by allowing equiproportional desirable output expansion and undesirable output contraction.

In all the aforementioned models the negative externality is included in the technology so the externality therefore influences productive performance (i.e. efficiency and TFP growth). We use exclusively parametric techniques in our empirical analysis and as an alternative to the above models we refer to the theoretical environmental economics literature which posits that TFP influences environmental quality (Chimeli and Braden, 2005; Chimeli, 2007). Along these lines we adopts a two-stage empirical methodology. First, we obtain two estimates of productive performance for European countries (technical efficiency and TFP growth) which have a wellestablished foundation as they are obtained in Stage 1 using the stochastic production frontier framework, from which we omit pollutants. Second, in Stage 2 these measures of productive performance are used as regressors in models of per capita emissions of nitrogen and sulphur oxides $\left(N O_{x}\right.$ and $\left.S O_{x}\right)$ for European countries. ${ }^{2}$ In the Stage 2 models we explicitly account for

\footnotetext{
${ }^{1}$ The approach in Reinhard et al. (1999; 2000) and Glass et al. (2013) involves estimating a standard input distance frontier where the negative externality is modelled as an input. Atkinson and Dorfman (2005), on the other hand, use an input distance frontier but instead of the negative externality being modelled as an input, the externality is allowed to shift the best practice frontier.

${ }^{2}$ We can include both efficiency and TFP growth as regressors in models of per capita $N O_{x}$ and $S O_{x}$ emissions to capture different aspects of productive performance for two reasons. Firstly, in contrast to TFP growth, efficiency is a level variable. Secondly, it will become clear further in the paper that the efficiency change component of TFP growth is relatively small. In addition, although we are not aware of an empirical study which uses measures of productive performance from a fitted stochastic frontier model as independent variables in a second-stage model of emissions, this approach is common in the extensive literature on banking efficiency. For example, Wheelock and Wilson (2000) use cost inefficiency as an explanatory variable in a model of competing risks in U.S. banking; Cipollini and Fiordelisi (2012) explain the financial distress of European banks using, among other things, profit efficiency; and cost efficiency is a regressor in a model of bank competitiveness in Casu and Giradone (2009).
} 
the spatial dependence of per capita $N O_{x}$ and $S O_{x}$ emissions.

We focus on $\mathrm{NO}_{x}$ and $\mathrm{SO}_{x}$ rather than other pollutants such as carbon dioxide $\left(\mathrm{CO}_{2}\right)$ because the case for spatial modelling of $N O_{x}$ and $S O_{x}$ is now well-established (see, for example, Maddison, 2006; 2007). More specifically, there are two arguments for spatial modelling of $N O_{x}$ and $S O_{x}$. The first relates to $N O_{x}$ and $S O_{x}$ being transboundary pollutants which in the context of the models we estimate in Stage 2 means that a proportion of emissions which relate to economic activity in one European country come to rest in another European country because of things such as the prevailing wind direction and the distance emissions travel. ${ }^{3}$ On the other hand, $\mathrm{CO}_{2}$ differs from $\mathrm{NO}_{x}$ and $\mathrm{SO}_{x}$ as it is a global pollutant so emissions from any country in the world will contribute to global warming and thus have a worldwide impact. Moreover, because of the availability of rich meteorological source-receptor tables for $N O_{x}$ and $S O_{x}$ as a result of the European Monitoring and Evaluation Program (EMEP), we capture the differences in the transboundary nature of $N O_{x}$ and $S O_{x}$ across European countries in the spatial modelling in Stage 2. This is because the source-receptor tables contain the amount of emissions that relate to economic activity in one European country but which travel to each of the other European countries in the sample. ${ }^{4}$ Following some simple manipulation of the source-receptor tables we obtain the spatial weights matrices for the per capita $N O_{x}$ and $S O_{x}$ models in Stage 2. To illustrate, from the annual source-receptor tables over the period 1997 - 2008, the average fraction of $N O_{x}$ and $S O_{x}$ emissions which are deposited outside a country's own borders range from $28 \%$ (Spain)-98\% (Moldova) and from 14\% (Spain)-95\% (Latvia), respectively. ${ }^{5}$

The second argument for spatial modelling of $N O_{x}$ and $S O_{x}$ is a theoretical one and also relates to the transboundary nature of the pollutants, which gives rise to the possibility of game playing between European countries. As we have noted above, a large proportion of the $N O_{x}$ and $S O_{x}$ emissions for some European countries come to rest outside their borders, whereas for others only a small proportion of their emissions travel to countries elsewhere in Europe. In the classic 'acid rain game' (e.g. Halkos and Hutton, 1993) the emissions of sulphur dioxide $\left(\mathrm{SO}_{2}\right)$ for European countries are interdependent because countries respond to transboundary deposition of pollution by adjusting their domestic emissions. In particular, for 27 European countries Halkos and Hutton (1993) show that acid rain in Europe from $\mathrm{SO}_{2}$ emissions causes greater environmental

\footnotetext{
${ }^{3}$ Most emissions of a transboundary pollutant are internalised (i.e. emissions come to rest within the borders of the country which is responsible) as they fall to ground in their dry form within $300 \mathrm{~km}$ of the source. Sulphuric acid rain, on the other hand, is often externalised (i.e. it comes to rest outside of the borders of the country which is responsible) as it can have a long-range impact and may fall to ground up to 2, $000 \mathrm{~km}$ from its source (Maddison, 2007).

${ }^{4}$ As pointed out by an anonymous referee, Anselin (2001) outlines some of the issues which arise when using spatial econometric techniques to model environmental quality. To illustrate, one issue which is often encountered is the spatial scale mismatch between economic data for adminstrative units and the measurment of environmental quality which may take the form of values for a regular grid of squares or pixels. This is not an issue in our empirical analysis because the economic data, emissions data and EMEP source-receptor tables all relate to individual European countries.

${ }^{5}$ As a result, relatively little of the impact associated with $N O_{x}$ and $S O_{x}$ emissions is felt by countries such as Moldova and Latvia. To illustrate, gaseous sulphur dioxide emissions have been found to preceed small particulate matter which have been linked to premature mortality (Pope et al., 1995). Also, these particles impair visibility in urban areas and are thought to alter planetary reflectivity masking temporarily the effects of climate change (Stern and Kaufman, 2000).
} 
damage when countries do not cooperate. ${ }^{6}$ This is because for a European country its privately efficient level of emissions are higher than its emissions under the efficient cooperative solution. ${ }^{7}$

In Stage 1 we estimate non-spatial and local spatial stochastic production frontier models. Likelihood ratio (LR) tests indicate that all eleven local spatial frontier models are preferred to the non-spatial frontier model. Furthermore, we use the Akaike Information Criteria (AIC) and the Bayesian Information Criteria (BIC) to choose between the local spatial frontier models. When we use the technical efficiency and TFP growth variables from our preferred local spatial frontier model as regressors in the spatial models of per capita $N O_{x}$ and $S O_{x}$ emissions, in both models only TFP growth has significant effect. In particular, we find that TFP growth from our preferred local spatial frontier model has a positive and marked effect in the spatial models of per capita $N O_{x}$ and $S O_{x}$ emissions. Putting these results into context, if it assumed that TFP growth falls across Europe then the spatial models of per capita $N O_{x}$ and $S O_{x}$ emissions predict, on average, that: (i) TFP growth of a European country would have to fall by $5.83 \%$ to achieve a $10 \%$ fall in its per capita $N O_{x}$ emissions; and (ii) TFP growth of a European country would have to fall by $2.04 \%$ to achieve a $10 \%$ fall in its per capita $S O_{x}$ emissions. In both these cases the fall in a country's TFP growth to achieve a $10 \%$ fall in per capita emissions is smaller than the corresponding non-spatial model predicts. This is because with the spatial specification, some of the fall in a country's per capita emissions is due to a fall in TFP growth spillovers coming to the country, which is overlooked by the non-spatial specification.

Førsund and Hjalmarsson (1988) highlight the implications of the choice of technology in energy intensive industries for long run technical change, where technical change is an important determinant of energy usage and hence emissions. Given our spatial models of per capita $N O_{x}$ and $S O_{x}$ emissions predict that further reductions in per capita emissions would be at the expense of a country's TFP growth, we conclude that the easiest reductions in per capita emissions from using newer capital which also leads to a rise in TFP growth have already occurred. This is entirely plausible because in the EU $N O_{x}$ and $S O_{x}$ emissions have been tightly regulated for some time via air quality standards. For example, to meet progressively tighter air quality standards there has been widespread installation of 'scrubbers' by EU coal-fired power plants to reduce $\mathrm{SO}_{2}$ emissions. ${ }^{8}$ In the context of stringent regulation of EU air quality, it is reasonable therefore to conclude from our empirical results that the development and diffusion of new greener technology is key to further reductions in per capita $N O_{x}$ and $S O_{x}$ emissions. More specifically, renewable energy technology undoubtedly has a big role to play in further reductions of per capita $N O_{x}$ and $S O_{x}$ emissions and is the subject of very recent work by Førsund and Hjalmarsson (2011).

The remainder of this paper is organised as follows. Section 2 discusses how we account for the spatial dependence in the cross-sections. In Section 3 we set out Stages 1 and 2 of the empirical methodology. Section 4 discusses the data and the specification of the spatial weights matrices. In Section 5, the empirical results are presented and analysed. We conclude in Section 6 by

\footnotetext{
${ }^{6}$ Countries do not cooperate when each country only considers the national marginal damage of its emissions. Alternatively, countries cooperate when each country considers the marginal damage of its emissions across Europe.

${ }^{7}$ See Figure 10.15 in Perman et al. (2003).

${ }^{8} \mathrm{An} \mathrm{SO}_{2}$ scrubber system is the informal name for flue gas desulphurisation technology, which removes or 'scrubs' $\mathrm{SO}_{2}$ emissions from the exhaust of coal-fired power plants.
} 
summarising the salient features of the methodology and the key empirical findings.

\section{Accounting for Spatial Dependence and Related Liter- ature}

In Stage 1 of the empirical methodology we incorporate spatial dependence into the SFA by allowing spatial lags of the inputs and spatial lags of the exogenous variables to shift the production frontier technology. The spatial lags of these variables depend on the spatial weights matrix which must be specified in advance of estimating the model. In Stage 1 we use eleven specifications of the spatial weights matrix, where the specifications are weighted by various proxies for economic distance or various proxies for geographical-economic distance. The first specification of the spatial weights matrix in Stage 1 is a comprehensive proxy for economic distance and involves constructing a dense specification of the spatial interaction by using all the pairwise import flows as spatial weights. We also use ten sparse specifications of the spatial weights matrix in Stage 1, all of which are subsets of the matrix weighted by the full set of import flows. Specifically, five of the ten sparse specifications are proxies for economic distance where the spatial weights are imports on a country's biggest $3-7$ import flows. The other five sparse specifications are proxies for geographical-economic distance, where the weights are imports on a country's nearest $3-7$ import flows. In Section 4 we discuss these spatial weights matrices in more detail. We also recognise that economic distance between two countries will differ depending on the direction. We therefore provide a justification for using import flows rather than export flows as a proxy for economic distance.

Putting the Stage 1 methodology into context, it makes a contribution to the small body of literature on spatial stochastic frontier modelling. A small number of studies estimate stochastic frontier models which account for global spatial dependence (i.e. first order neighbour effects through to $(N-1)$ th order neighbour effects) and calculate efficiency using the cross-sectional specific effects. The first of these studies is due to Druska and Horrace (2004), who propose a GMM spatial error stochastic frontier model with fixed effects which is an extension of Kelejian and Prucha's (1999) specification for cross-sectional data. Specifically, they model global spatial dependence in production by including the spatial error term in the set of variables which shift the production frontier technology. They then calculate time-invariant efficiency from the crosssectional specific effects using the Schmidt and Sickles (1984) panel data method. Glass et al. (2013b; 2014) adopt a similar approach by following Cornwell et al. (1990) and using the fixed effects from a spatial lag stochastic frontier model to estimate time-varying efficiency. With the Druska and Horrace (2004) specification, the spillover marginal effect relates to the disturbance. This effect, however, is not as informative as spillover effects which relate to the explanatory variables, as is the case in Glass et al. (2013b; 2014) and for the local spatial stochastic frontier model which we propose here. In addition, the local spatial stochastic frontier model which we set out in Stage 1 differs from the models in Druska and Horrace (2004) and Glass et al. (2013b; 2014) because rather than calculate efficiency from the cross-sectional specific effects, we calculate efficiency by making an assumption about the distribution of the inefficiency component of the 
error term.

By introducing spatial lags of the inputs and spatial lags of the exogenous variables, all of which shift the production frontier technology, we apply to SFA the approach used in Baltagi and Levin (1986) and Baltagi et al. (2000) to analyse how cigarette demand in a U.S. state is affected by cigarette prices in neighbouring states. Although this approach only captures local spatial dependence (i.e. first order neighbour effects), it is a simple way to account for spatial interaction. This is because, as is highlighted in Baltagi and Levin (1986) and Baltagi et al. (2000), the local spatial variables are not endogenous so a local spatial stochastic frontier model can be estimated using standard Maximum Likelihood (ML) procedures. Unlike a fitted local spatial stochastic frontier model where the parameters can be interpreted as elasticities, if we estimated a stochastic frontier model which accounts for global spatial dependence via a spatial lag of the dependent variable, the coefficients on the independent variables cannot be interpreted as elasticities (LeSage and Pace, 2009). This is because the marginal effect of an independent variable is a function of the spatial lag variable. To disentangle the effect of an independent variable from the effect of the spatial lag variable, LeSage and Pace (2009) propose an approach to calculate direct (i.e. own) and indirect (i.e. spillover) elasticities.

In Stage 2 we estimate spatial lag models for per capita $N O_{x}$ and $S O_{x}$ emissions because as we noted above, and importantly unlike the spatial error model, with the spatial lag specification we can distinguish between the direct and indirect marginal effects of the independent variables. The average direct effect estimates the average impact of changing an independent variable in a particular cross-sectional unit on that unit's dependent variable, and takes into account feedback effects (i.e. effects which pass through first order neighbours and higher order neighbours via the spatial multiplier matrix and back to the unit which initiated the change). The average indirect effect can be calculated two ways which yield estimates of the same magnitude. The first way of calculating the average indirect effect estimates the average impact on one unit's dependent variable following a change in an independent variable for all the other units. The second way estimates the average impact of a change in an independent variable for one unit on the dependent variable of all the other units. The average total effect of an independent variable is the sum of the average direct and average indirect elasticities. By calculating and interpreting the direct, indirect and total marginal effects, we extend recent studies which estimate the spatial lag model to analyse sulphur emissions for European countries (Ivanova, 2011; Maddison, 2006; 2007).

\section{Empirical Methodology}

\subsection{Efficiency and Productivity Analysis in Stage 1}

\subsubsection{A Stochastic Frontier Model with Local Spatial Dependence}

Technical efficiency is the first aspect of productive performance which is used as an independent variable in the spatial lag models of per capita $N O_{x}$ and $S O_{x}$ emissions. Sets of efficiency scores are obtained from non-spatial and local spatial stochastic frontier models. The local spatial stochastic frontier models for panel data which we estimate have the following form, where lower 
case letters denote logged variables unless otherwise stated.

$$
\begin{aligned}
y_{i t} & =\kappa+T L\left(x_{i t}, t\right)+z_{i t} \tau+\sum_{j=1}^{N} w_{i j} x_{j t} \phi+\sum_{j=1}^{N} w_{i j} q_{j t} \eta+v_{i t}-u_{i t}, \\
i & =1, \ldots N ; t=1, \ldots, T
\end{aligned}
$$

where $N$ is a cross-section of units operating over a fixed time dimension $T, y_{i t}$ is the output of the $i$ th unit at time $t$ and $\kappa$ is the intercept parameter. $x_{i t}$ is a $(1 \times R)$ vector of input levels, $t$ is a time trend and $T L\left(x_{i t}, t\right)=x_{i t} \gamma+\frac{1}{2} x_{i t}^{\prime} \Theta x_{i t}+\rho_{1} t+\rho_{2} t^{2}+x_{i t} t \xi$ represents the technology as the translog approximation of the $\log$ of the production function, where $\gamma$ is a vector of parameters and $\Theta$ is a matrix of parameters to be estimated. When estimating a country production function, a Cobb-Douglas specification is often used which may involve imposing constant returns to scale. We, however, use the flexible translog specification which, unlike the Cobb-Douglas function, allows returns to scale to vary at every point in the sample. Since we use the estimation results for Eq. 1 to compute TFP growth over the sample by summing its three components (technical change, efficiency change and scale change), by allowing returns to scale to vary we do not assume at every point in the sample that the scale change component of TFP growth is zero. In addition, $z_{i t}$ is a $(1 \times M)$ vector of exogenous characteristics for the ith unit, $x_{j t}$ is a $(1 \times R)$ vector of input levels for the $j$ th neighbouring unit and $q_{j t}$ is a $(1 \times P)$ vector of exogenous characteristics for the $j$ th neighbouring unit, where $\tau, \phi$ and $\eta$ are vectors of parameters to be estimated.

$w_{i j}$ is the known $i j t h$ element of the $(N \times N)$ spatial weights matrix, W. W captures the spatial arrangement of the cross-sectional units and also the strength of the spatial interaction in the cross-sections. W must be specified prior to estimation and is usually specified according to some measure of geographical or economic proximity. As is standard in applied spatial econometrics, all the diagonal elements of $\mathbf{W}$ are set to zero to recognise that no unit can be its own neighbour and we also use a row-normalised $\mathbf{W}$. W is normalized to have row sums of unity so that a spatially lagged variable is a weighted average of observations for neighbouring units, which preserves the scaling of the data for neighbouring units across space and thus facilitates interpretation. Whereas only the $z$ variables shift the production frontier technology for the non-spatial counterpart of Eq. 1, the $z$ variables, the spatial lags of the inputs $\left(\sum_{j=1}^{N} w_{i j} x_{j t} \phi\right)$ and the spatial lags of the exogenous variables $\left(\sum_{j=1}^{N} w_{i j} q_{j t} \eta\right)$ all shift the production frontier technology in Eq. 1.

As is standard in SFA, the error structure is $\varepsilon_{i t}=v_{i t}-u_{i t}$, where it is assumed that $\varepsilon_{i t}$ is the observed deviation from the best practice production frontier, $v_{i t}$ is the symmetric normally distributed idiosyncratic error term, $v_{i t} \sim N\left(0, \sigma_{v}^{2}\right), u_{i t}$ is a non-negative error term which measures time-variant inefficiency, and $v_{i t}$ and $u_{i t}$ are both i.i.d. Specifically, it is assumed that $u_{i t}$ follows a truncated normal distribution, where the distribution has a mean $\mu$ and is truncated at zero, $u_{i t} \sim\left|N\left(\mu, \sigma_{u}^{2}\right)\right|$. This is a more flexible assumption than assuming that $u_{i t}$ follows a non-negative half-normal distribution with a mean of zero, $u_{i t} \sim\left|N\left(0, \sigma_{u}^{2}\right)\right|$ (see Stevenson, 1980, for further details). 


\subsubsection{Generalised Malmquist TFP Growth}

The second aspect of productive performance which is used as a regressor in the spatial lag models of per capita $N O_{x}$ and $S O_{x}$ emissions is TFP growth. For the technology in Eq. 1, TFP growth is the rate of growth of output minus the rate of growth in a multiple input quantity index. Orea (2002) notes that any TFP growth index should be characterised by four properties: (i) identity, (ii) monotonicity, (iii) separability and (iv) proportionality. The implications of the four properties for a production frontier technology are as follows. Identity requires that if inputs and output do not change, the TFP growth index is unity. Monotonicity requires that the weighted input growth rate is chosen so that higher output and a lower input unambiguously improve TFP growth. Separability, which is a property of the technology set of Eq. 1, permits generalization from a single output and a single input to multiple inputs in the case of Eq. 1. Finally, proportionality requires that the weights for the input growth index sum to unity. Specifically, the measure of TFP growth which we use is a Generalised Malmquist TFP index. Coelli et al. (2003) demonstrate that a Generalised Malmquist TFP index which satisfies the above properties can be constructed from the translog approximation of the production function. Since $\ln T E_{i t}=-u_{i t}$, where $T E$ denotes technical efficiency, and by making use of the quadratic identity lemma (Caves et al., 1982) the following expression for $\ln T F P G_{i t+1}$ can be obtained.

$$
\begin{gathered}
\ln T F P G_{i t+1}=\left[\ln T E_{i t+1}-\ln T E_{i t}\right]+\frac{1}{2}\left[\left(\partial y_{i t+1} / \partial t\right)+\left(\partial y_{i t} / \partial t\right)\right] \\
+\left[\frac{1}{2} \sum_{r=1}^{r=R}\left(\left(e x_{r, i t+1} S F_{i t+1}\right)+\left(e x_{r, i t} S F_{i t}\right)\right)\left(x_{r, i t+1} / x_{r, i t}\right)\right]
\end{gathered}
$$

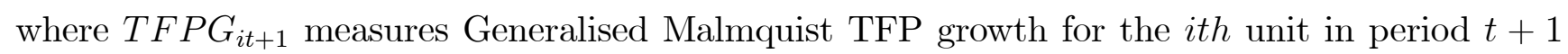
and $e x_{r}$ is a column vector of input elasticities $(r=1, \ldots, R) . S F$ is the scale factor (see Saal $e t$ al., 2007):

$$
S F=\left(\frac{\sum_{r=1}^{r=R} e x_{r}+1}{\sum_{r=1}^{r=R} e x_{r}}\right)=1-R T S,
$$

and $R T S$ is the scale elasticity of the technology:

$$
R T S=-\left(\frac{\partial y}{\sum_{r=1}^{r=R} \partial x_{r}}\right)^{-1} \equiv\left(\sum_{r=1}^{r=R} e x_{r}\right)^{-1}
$$

The three terms in square brackets in Eq. 2 represent the familiar Generalised Malmquist decomposition of TFPG into efficiency change, EC, technical change, $T C$, and scale change, $S C$ :

$$
T F P G=E C+T C+S C
$$

Using the estimates of technical efficiency and the first order and second order elasticity and scale parameters from the fitted translog stochastic production frontier (Eq. 1) we calculate EC, TC 
and $S C$ and sum to obtain TFPG.

\subsection{Spatial Lag Model in Stage 2}

The specification of the spatial lag model for panel data which we estimate is:

$$
e_{i t}=\delta \sum_{j=1}^{N} w_{i j} e_{j t}+\alpha+g_{i t} \beta+\psi_{i}+\varepsilon_{i t},
$$

where $e_{i t}$ is per capita emissions of $N O_{x}$ or $S O_{x}$ for the $i t h$ country at time $t, \alpha$ is the intercept parameter, $g_{i t}$ is a $(1 \times K)$ vector of observations for the independent variables where $k=1, \ldots, K$, and $\beta$ is a $(K \times 1)$ vector of parameters to be estimated. $\psi_{i}$ is a unit specific time-invariant effect to capture unobserved heterogeneity (fixed effects, FEs, or random effects, REs) and $\varepsilon_{i t}$ is an i.i.d disturbance for $i$ and $t$ with zero mean and variance $\sigma^{2} . w_{i j}$ in Eq. 1 differs from $w_{i j}$ in Eq. 4 because the spatial weights matrices are pre-specified differently. Otherwise the above discussion of $\mathbf{W}$ for Eq. 1 also applies here. The inclusion of the spatial lag term, $\delta \sum_{j=1}^{N} w_{i j} e_{j t}$, in Eq. 4 captures the global spatial dependence of the dependent variable. $\delta$ is the spatial lag parameter and as is standard in applied spatial econometrics we make the following assumptions. (i) $(\mathbf{I}-\delta \mathbf{W})$ is non-singular and the parameter space of $\delta$ is $\left(\frac{1}{f_{\min }}, 1\right)$, where $\mathbf{I}$ is the $(N \times N)$ identity matrix and $f_{\min }$ is the most negative real characteristic root of $\mathbf{W}$. Since we use a rownormalised $\mathbf{W}$ in Stage 2, 1 is the largest real characteristic root of $\mathbf{W}$ which rules out explosive growth. (ii) The row and column sums of $\mathbf{W}$ and $(\mathbf{I}-\delta \mathbf{W})$ are bounded uniformly in absolute value before $\mathbf{W}$ is row-normalized. As a result of this assumption the spatial process for the dependent variable has a 'fading' memory (e.g. Kelejian and Prucha, 1998; 2010).

We estimate the spatial lag specification rather than a spatial error model because the spatial lag term is a more explicit representation of global spatial dependence than the spatial error term. Consequently, as we noted above, from a spatial lag model we can estimate indirect elasticities for the $g$ variables. From a spatial error model, however, the only indirect elasticity which can be estimated is for $\varepsilon$, which is not particularly informative. LeSage and Pace (2009) suggest the following approach to calculate the direct, indirect and total marginal effects for the $g$ variables and the associated significance levels. Stacking successive cross-sections we can rewrite Eq. 4 as follows:

$$
e_{t}=(\mathbf{I}-\delta \mathbf{W})^{-1} \alpha \iota+(\mathbf{I}-\delta \mathbf{W})^{-1} \psi+(\mathbf{I}-\delta \mathbf{W})^{-1} \mathbf{G}_{t} \beta+(\mathbf{I}-\delta \mathbf{W})^{-1} \varepsilon_{t},
$$

where $e_{t}$ is an $(N \times 1)$ vector of stacked observations for per capita $N O_{x}$ or $S O_{x}$ emissions, $\iota$ is an $(N \times 1)$ vector of ones, $\psi$ is an $(N \times 1)$ vector of FEs or REs, $\mathbf{G}_{t}$ is an $(N \times K)$ matrix of stacked observations for the independent variables and $\varepsilon_{t}$ is an $(N \times 1)$ vector of stacked idiosyncratic disturbances. Differentiating Eq. 5 with respect to the $k t h$ independent variable, $g_{k, t}$, yields the following vector of partial derivatives: 


$$
\begin{aligned}
{\left[\begin{array}{llll}
\frac{\partial e}{\partial g_{k, 1}} & \frac{\partial e}{\partial g_{k, 2}} \cdot \cdot \frac{\partial e}{\partial g_{k, N}}
\end{array}\right]_{t}=\left[\begin{array}{ccccc}
\frac{\partial e_{1}}{\partial g_{k, 1}} & \frac{\partial e_{1}}{\partial g_{k, 2}} & \cdot & \cdot & \frac{\partial e_{1}}{\partial g_{k, N}} \\
\frac{\partial e_{2}}{\partial g_{k, 1}} & \frac{\partial e_{2}}{\partial g_{k, 2}} & \cdot & \cdot & \frac{\partial e_{2}}{\partial g_{k, N}} \\
\cdot & \cdot & \cdot & \cdot & \cdot \\
\cdot & \cdot & \cdot & \cdot & \cdot \\
\frac{\partial e_{N}}{\partial g_{k, 1}} & \frac{\partial e_{N}}{\partial g_{k, 2}} & \cdot & \cdot & \frac{\partial e_{N}}{\partial g_{k, N}}
\end{array}\right]_{t} } \\
=(\mathbf{I}-\delta \mathbf{W})^{-1}\left[\begin{array}{ccccc}
\beta_{k} & 0 & \cdot & \cdot & 0 \\
0 & \beta_{k} & \cdot & \cdot & 0 \\
\cdot & \cdot & \cdot & \cdot & \cdot \\
\cdot & \cdot & \cdot & \cdot & \cdot \\
0 & 0 & \cdot & \cdot & \beta_{k}
\end{array}\right],
\end{aligned}
$$

where the right-hand side of Eq. 6b is independent of the time index. Since either Eq. 6a or Eq. $6 \mathrm{~b}$ yield different direct (i.e. own) and indirect (i.e. spillover) elasticities for each unit, to facilitate interpretation LeSage and Pace (2009) suggest reporting a mean direct elasticity (average of the diagonal elements on the right-hand side of Eq. 6b), a mean indirect elasticity (either the average row sum or average column sum of the non-diagonal elements on the right-hand side of Eq. 6b which yield estimates of the mean indirect elasticity of the same magnitude) and a mean total elasticity (sum of the mean direct and mean indirect elasticities).

Calculation of the mean direct, mean indirect and mean total elasticities is straightforward but calculation of the associated significance levels is less so. This is because having estimated Eq. 4 , it cannot be established from the $t$ statistics derived from the variance-covariance matrix whether the mean direct, mean indirect and mean total elasticities are significant. This is because, as we have seen from Eq. 6b, the mean direct, mean indirect and mean total elasticities are calculated using a number of coefficients and the dispersion of the mean direct, mean indirect and mean total elasticities therefore depends on the dispersion of all the coefficient estimates used to calculate these elasticities. LeSage and Pace (2009) therefore propose Bayesian MCMC simulation of the distributions of the mean direct, mean indirect and mean total effects using the variance-covariance matrix associated with the ML estimates. This involves drawing 1,000 parameter combinations of $\left(\hat{\delta}, \hat{\beta}, \hat{\sigma}^{2}\right)$ from the variance-covariance matrix where each parameter has a random component drawn from a normal distribution with a mean of zero and a standard deviation of one. Mean direct, mean indirect and mean total elasticities are then calculated for each parameter combination using the right-hand side of Eq. 6b. The mean elasticities which we report are the averages over the 1,000 estimates of the mean effects. The associated $t$ statistics are obtained by dividing the reported mean elasticity by the standard deviation across the corresponding 1,000 mean elasticities.

A spatial lag model can be estimated parametrically using ML, GMM and Bayesian MCMC. Here we follow the procedure in Elhorst (2009) and use ML to estimate Eq. 4. The estimation of Eq. 4 has a number of important features. Firstly, since the spatial lag variable is endogenous, the assumption of the standard regression model that $E\left[\left(\sum_{j=1}^{N} w_{i j} e_{j t}\right) \varepsilon_{i t}\right]=0$ is violated. We 
adjust for this endogeneity and also the fact that $\varepsilon_{t}$ is not observed in the usual way by introducing to the log-likelihood function the scaled logged determinant of the Jacobian of the transformation from $\varepsilon_{t}$ to $e_{t}$ (i.e. include as a term in the log-likelihood function $T \ln |\mathbf{I}-\delta \mathbf{W}|$ ). Secondly, when we account for the time-invariant unobserved heterogeneity in Eq. 4 using FEs, we demean in space to circumvent the incidental parameter problem associated with the FEs, which eliminates these effects (and the intercept). Lee and Yu (2010) show that demeaning in space to estimate a FEs spatial model which contains the spatial lag variable results in a biased estimate of $\sigma^{2}$ if $N$ is large and $T$ is fixed, which we denote $\sigma_{B}^{2}$ where the bias is of the type identified in Neyman and Scott (1948). Following Lee and Yu (2010) and Elhorst (2012) we correct for this bias by replacing $\sigma_{B}^{2}$ with the bias corrected estimate of $\sigma^{2}, \sigma_{B C}^{2}=\frac{T \sigma^{2}}{(T-1)}$, which changes the standard errors. Thirdly, when we account for the time-invariant unobserved heterogeneity using REs and as a result, $\psi_{i}$ in Eq. 4 denotes the ith element of a random variable $\psi$ which is i.i.d with zero mean and variance $\sigma_{\psi}^{2}$; an additional parameter, $\varsigma=\sigma_{\psi}^{2} / \sigma^{2}$, is introduced to Eq. 4 which denotes the weight attached to the variation in the cross-sections.

\section{Data and Specification of the W Matrices}

Throughout Stages 1 and 2 of the analysis the data is for 40 European countries which is a good representative sample of Europe with only a relatively small number of countries omitted to obtain a balanced panel for Stage 2, which is a standard approach in applied spatial econometrics. ${ }^{9}$ See Appendix 1 for a complete list of the 40 countries. The sample period for the SFA in Stage 1 is $1995-2008$ so the study period for the calculation of TFP growth in Stage 1 and the estimation of the spatial lag models in Stage 2 is 1996 - 2008. The data for Stages 1 and 2 is logged where it is appropriate and the continuous variables which relate to the SFA are then normalised around their mean values so we can interpret the first order parameters from the translog function as elasticities. In Stage 1, output is real GDP in 2005 international dollars, $y$, and the first input is the labour input and is the number of people engaged, $x_{1}$. The second input is real capital stock in 2005 international dollars, $x_{2}$.

To calculate $y, x_{1}$ and $x_{2}$ we follow Badunenko et al. (2008). We extracted data for the following variables from the Penn World Table Version 7.0 (Heston et al., 2011), PWT 7.0: real GDP per capita in 2005 international dollars calculated using the Laspeyres index and the chain method, denoted as rgdpl and rgdpch in PWT 7.0; population, pop; real GDP per worker calculated using the chain method, rgdpwok; and investment as a share of $r g d p l$, ki. Recently, Johnson et al. (2013) reestimated a number of classic empirical macroeconomic models using different vintages of the Penn World Table. They conclude that the estimation results are not robust across the different vintages. It will become apparent, however, that we obtain reasonable estimates of the key input elasticities at the sample mean using data from PWT7.0.

\footnotetext{
${ }^{9}$ Although global spatial estimators such as that which we use in Stage 2 can be extended to unbalanced panel data, their asymptotic properties may become problematic if the reason why data are missing is not known (Elhorst, 2009). Extending global spatial estimators from balanced to unbalanced panel data therefore involves making a strong assumption about why observations are missing. For example, Pfaffermayr (2013) assumes that data are missing at random for an unbalanced spatial panel.
} 
$x_{1}=(r g d p c h * p o p) / r g d p w o k, y=x_{1} * r g d p w o k$ and we estimate the data for $x_{2}$ in two steps. Firstly, we calculate real aggregate investment which is $r g d p l * p o p * k i$. Secondly, real capital stock in 1995 is assumed to be depreciated real aggregate investment in 1994, where we follow much of the literature on estimating capital stock and use a depreciation rate of $6 \% .{ }^{10}$ Real capital stock for the remainder of the sample is then estimated using the perpetual inventory method. $z$ in Eq. 1 is a $(1 \times 4)$ vector of the following variables: (i) arable land as a share of total land, $z_{1}$, where the data is from the World Bank; (ii) sum of imports and exports as a share of GDP (i.e. trade openness), $z_{2}$; (iii) government spending as a share of GDP, $z_{3}$, where the data for $z_{2}$ and $z_{3}$ is from PWT 7.0; and (iv) a dummy variable for EU membership, $z_{4} . \mathbf{W} q$ is a $(1 \times 3)$ vector of spatial lags of the $z_{1}, z_{2}$ and $z_{3}$ variables. We omit a spatial lag of the $z_{4}$ variable to avoid perfect collinearity. If we included a spatial lag of $z_{4}$, the $z_{4}$ and $\mathbf{W} z_{4}$ variables would be perfectly collinear because $z_{4}=\mathbf{W} z_{4}$. This is because pre-multiplying a dummy variable by a spatial weights matrix yields the dummy variable. For the same reason we do not include spatial lags of $t$ and $t^{2}$ as exogenous characteristics, although to account for own technical progress we include $t, t^{2}$ and the cross terms including $t$ as part of the technology.

Eq. 1 is estimated using eleven row-normalised specifications of $\mathbf{W}$. The spatial weights in all eleven specifications are calculated using data from the IMF Direction of Trade Statistics database on import flows in 2000 US dollars for the period $2000-2008$. The first specification of $\mathbf{W}$ is a densely specified comprehensive proxy for economic distance and is denoted $\mathbf{W}_{\text {All }}$. $\mathbf{W}_{\text {All }}$ is constructed by using the average real imports of the $i t h$ country from each of the other countries in the sample as spatial weights. The other ten specifications of $\mathbf{W}$ are sparsely populated, five of which are proxies for geographical-economic distance (denoted $\mathbf{W}_{3 \text { Near }}, \ldots, \mathbf{W}_{7 \text { Near }}$ ) and use as spatial weights average real imports of the ith country from the nearest $3-7$ countries according to distances between capital cities. The remaining five specifications of $\mathbf{W}$ are additional proxies for economic distance (denoted $\mathbf{W}_{3 B i g}, \ldots, \mathbf{W}_{7 B i g}$ ) and use as spatial weights average real imports of the ith country on its biggest $3-7$ real import flows. Finally, we note that economic distance or geographical-economic distance between two countries will differ depending on the direction. Put another way, economic distance or geographical-economic distance between two countries will differ depending on whether the spatial weights are based on real import flows or real export flows. For Stage 1, the weights are based on average real import flows. This is because the spatial lags of the inputs and the spatial lags of the exogenous characteristics are weighted averages of the observations for some/all of the other countries in the sample and imports is a more appropriate indicator of the extent to which a country draws on, for instance, the labour force and the capital stock of another country in the sample.

For the spatial lag models in Stage 2, the dependent variable is per capita emissions of nitrogen oxides, $N O_{x} / P o p$, or per capita emissions of sulphur oxides, $S O_{x} / P o p$. The $N O_{x}$ and $S O_{x}$ emissions data is that which is used in the EMEP models and reports. We do not use the $N O_{x}$

\footnotetext{
${ }^{10}$ We thank Joseph Pearlman for suggesting this approach to estimate real capital stock for the first year of the sample. Although this is not the usual approach to estimate real capital stock for the first year of a sample, it will become apparent that the capital elasticities in Stage 1 using this approach are sensible. The conventional approach to estimate real capital stock for the first year of a sample is to use fully depreciated real GDP but this would require several years of additional data, which was not available for all the countries in the sample.
} 
and $S O_{x}$ emissions data which countries submit to EMEP because of missing observations and inaccuracies. For example, there can be inaccuracies because there is an incentive for countries to underreport emissions. In Figure 1 we present average annual per capita emissions of $N O_{x}$ and average annual per capita emissions of $S O_{x}$ over the study period for Stage 2. We also present as a comparator average annual per capita emissions of $\mathrm{CO}_{2}$. It is therefore evident that $\mathrm{NO}_{x} / \mathrm{Pop}$ and, in particular, $S O_{x} / P o p$ have fallen over the study period which is due to stringent regulation of both pollutants in the EU via air quality standards.

\section{[Insert Figure 1]}

The spatial weights matrices in Stage 2 are based on the 1997 - 2008 EMEP source-receptor tables for $N O_{x}$ and $S O_{x}$ emissions. These tables are also referred to as transport matrices or blame matrices. To obtain the spatial weights matrices we calculate average source-receptor tables for $N O_{x}$ and $S O_{x}$ over the above time period, set all the elements on the main diagonal equal to zero and row normalise. Each cell in the $N O_{x}$ and $S O_{x}$ spatial weights matrices refers to $w_{i j}$ and is the fraction of country $j$ 's total emissions which are deposited outside its borders in country $i$ (Ivanova, 2011). ${ }^{11}$

The independent variables in the Stage 2 spatial lag models are based on those used by Cole (2007) in his country level analysis of $\mathrm{SO}_{2}$ and $\mathrm{CO}_{2}$ emissions. Specifically, the regressors in the Stage 2 models are: (i) real GDP per capita (2005 international dollars in 000s), RGDP/Pop, where the data is from $P W T$ 7.0; (ii) $(R G D P / P o p)^{2}$ to capture the possibility of there being a threshold level of income below which per capita emissions rise and beyond which they fall i.e. an Environmental Kuznets Curve (EKC) relationship; ${ }^{12}$ (iii) sum of exports and imports as a share of GDP, Trade_Share, is included to capture the effect of trade openness, where the data is from $P W T 7.0 ;^{13}$ and (iv) value added by the industrial sector as a share of GDP, Ind_Share, where the data is from the World Bank. ${ }^{14}$ This core set of independent variables is then supplemented with TFPG and TE from a Stage 1 non-spatial or local spatial stochastic frontier model. The descriptive statistics for the continuous variables which are used in Stages 1 and 2 are presented in Table 1 and are for the raw data.

\footnotetext{
${ }^{11}$ As noted in 3.1.1 above, all the specifications of $\mathbf{W}$ in Stage 1 are row-normalized so the spatial lags of the inputs and exogenous variable which shift the production frontier technology in Eq. 1 are weighted averages of observations for neighbouring units. The specification of $\mathbf{W}$ in Stage 2 is also row-normalised. The spatial lag of the dependent variable in Stage 2 is therefore a weighted average of observations for the dependent variable for neighbouring units. As result, in Stages 1 and 2 spillovers are positively related to the relative (and not the absolute) measure of proximity used to configure $\mathbf{W}$.

${ }^{12}$ We control for the possibility of an EKC relationship but this is not a relationship which we focus on in this paper. This is because, firstly, the empirical focus of Stage 2 is the direct and indirect effects of TFPG and TE on $N O_{x} / P o p$ and $S O_{x} / P o p$. Secondly, the EKC literature is very well developed. For an up-to-date appraisal of the EKC literature see Carson (2010). Furthermore, we explored including ( $R G D P / P o p)^{3}$ to capture the possibility of a further turning point but for reasons which are explained in the analysis of the results this variable was dropped.

${ }^{13}$ The impact of trade on the environment is an issue which has received a lot of attention in recent years. We control for the effect of trade on the environment but we do not focus on this relationship in the analysis of the results because our interests lie elsewhere. For a recent survey of the literature on the trade-environment nexus see Frankel (2009).

${ }^{14}$ We follow the spatial analysis of sulphur emissions in Europe by Ivanova (2011) and do not include dummy variables for international environmental agreements (IEAs). This is because a lot of the empirical evidence on the effects of IEAs suggests that they are symbolic, as they mandate reductions in pollution which would have been achieved in their absence (e.g. Murdoch and Sandler, 1997; Murdoch et al., 1997). See Ivanova (2011) for a discussion of the empirical and game theoretic rationales for not including dummy variables relating to IEAs.
} 
[Insert Table 1]

\section{$5 \quad$ Results and Analysis}

\subsection{Efficiency and Productivity Results from Stage 1}

\subsubsection{Model Selection and Estimation Results for the Stochastic Frontier Models}

The non-spatial stochastic frontier model and all the local spatial stochastic frontier models are fitted using the Battese and Coelli (1992) time-varying decay estimator. As we touched on above, to test each of the eleven local spatial stochastic frontier models against the non-spatial model we perform a series of LR tests. The null hypothesis for each LR test is that the coefficients on the spatial lags of the inputs and the coefficients on the spatial lags of the exogenous characteristics are not jointly significant. For all the local spatial stochastic frontier models we reject the null at the $0.1 \%$ level, thereby justifying the inclusion of spatial lags of the inputs and spatial lags of the exogenous characteristics. ${ }^{15}$. Given that the LR tests favour each of the local spatial stochastic frontier models over the base non-spatial model, we adopt the approach which Pfaffermayr (2009) uses to choose between different spatial weights matrices for a spatial lag model and use the AIC to choose between the local spatial models. To check the robustness of the model selection using the AIC we also use the BIC. We have a strong preference for the $\mathbf{W}_{7 N e a r}$ as it yields the lowest values of the AIC and BIC. The values of the AIC and BIC support the LR test results, as we again favour the eleven local spatial stochastic frontier models over the non-spatial model because all the local spatial models have lower AIC and BIC values. The values of the AIC and BIC for the non-spatial and local spatial stochastic frontier models are presented in Appendix 2.

Notwithstanding that the time-varying decay estimator assumes that the annual rate of change in inefficiency is the same for all countries in the sample, the efficiency scores from our preferred $\mathbf{W}_{7 \text { Near }}$ local spatial model are sensible because, as we would expect, the five countries with the highest average efficiency scores over the study period are from Northern and Western Europe (1. Luxembourg; 2. UK; 3. Norway; 4. Netherlands; 5. Sweden) and the five countries with the lowest average efficiency scores are from Eastern Europe (40. Moldova; 39. Armenia; 38. Azerbaijan; 37. Ukraine; 36. Belarus). ${ }^{16}$ On economic grounds a case could be made for the $\mathbf{W}_{\text {All }}$ model over the other ten local spatial models because the other ten specifications of $\mathbf{W}$ are based on imports from a relatively narrow range of countries, when in reality a country imports from a much wider range of countries. Despite this economic case for the $\mathbf{W}_{\text {All }}$ model our preferred model is $\mathbf{W}_{7 \text { Near }}$. This is because the efficiency scores from the $\mathbf{W}_{\text {All }}$ model are not as reasonable as those from the $\mathbf{W}_{7 N e a r}$ model. For example, on average, three of the five most efficient countries over the study period from the $\mathbf{W}_{\text {All }}$ model are from eastern Europe (1. Macedonia; 2. Germany;

\footnotetext{
${ }^{15}$ To further illustrate, the LR test statistics range from $68.98\left(\mathbf{W}_{4 N e a r}\right)-180.35\left(\mathbf{W}_{7 N e a r}\right)$ for the eleven tests.

${ }^{16}$ We experimented with a range of other efficiency estimators by allowing the non-spatial and spatial variables which shift the frontier technology to also affect the mean of the pre-truncated inefficiency distribution or affect the variance of the inefficiency distribution and/or the variance of the idiosyncratic disturbance. Despite a number of countries in the sample being at different stages of development and transition we obtained the most sensible set of efficiencies using the time varying decay estimator.
} 
3. Greece; 4. Poland; 5. Lithuania). We revisit the efficiency estimates in more detail in 5.1.2.

The fitted parameters for the non-spatial stochastic frontier model and five local spatial stochastic frontier models, including our preferred $\mathbf{W}_{7 \text { Near }}$ model, are presented in Table $2 .{ }^{17}$ In the analysis of the estimation results for the non-spatial and local spatial stochastic frontier models we place the emphasis on comparing the findings from the non-spatial model and our preferred $\mathbf{W}_{7 \text { Near }}$ model, and only present the estimation results for other local spatial models for illustrative purposes.

\section{[Insert Table 2]}

All the input elasticities from the non-spatial and local spatial stochastic frontier models are significant at the $0.1 \%$ level and satisfy the monotonicity conditions at the sample mean as they are all positive. It is evident from Table 2 that the labour and capital elasticities from the nonspatial stochastic frontier model are 0.710 and 0.332, respectively. Again from Table 2 we can see that the labour elasticity from our preferred $\mathbf{W}_{7 N e a r}$ local spatial model falls to 0.570 and the capital elasticity rises to 0.435 when the local spatial variables are introduced. For the other local spatial stochastic frontier models $\left(\mathbf{W}_{\text {All }}, \mathbf{W}_{3 \text { Near }}-\mathbf{W}_{6 \text { Near }}\right.$ and $\left.\mathbf{W}_{3 \text { Big }}-\mathbf{W}_{7 \text { Big }}\right)$ the labour and capital elasticities range from $0.561-0.637$ and $0.406-0.440$, respectively. It is therefore evident that for all the non-spatial and local spatial frontier models the labour elasticity is larger than the capital elasticity, which is also what a number of key macroeconomic studies observe (e.g. Ireland, 2004, and Smets and Wouters, 2003). Irrespective of whether local spatial dependence is accounted for, production is always at least broadly characterised by constant returns to scale with an estimate of 1.042 from the non-spatial model, 1.005 from the $\mathbf{W}_{7 \text { Near }}$ model and estimates ranging from $0.989-1.049$ for the other local spatial frontier models. Finding evidence of constant returns to scale at the sample mean is consistent with the assumption of constant returns in classic macroeconomic theories (e.g. Ireland, 2004, and Smets and Wouters, 2003) and with evidence from key empirical macroeconomic studies (e.g. Burnside et al., 1995).

Moving on to briefly discuss some of the local spatial parameters. To present a clearer picture when discussing the results for some of the other local spatial variables, we focus on the findings from our preferred $\mathbf{W}_{7 \text { Near }}$ model. It is apparent from the fitted $\mathbf{W}_{7 \text { Near }}$ model in Table 2 that the coefficient on the spatial lag of the labour input $\left(\mathbf{W} x_{1}\right), \phi_{1}$, is positive, non-negligible and significant at the $0.1 \%$ level. This suggests that, on average, there are marked positive labour productivity spillovers from a country's nearest seven import partners. In contrast, the coefficient on the spatial lag of the capital input $\left(\mathbf{W} x_{2}\right), \phi_{2}$, from the fitted $\mathbf{W}_{7 \text { Near }}$ model is negative, non-negligible and significant at the $0.1 \%$ level. This indicates that, on average, there are non-negligible negative capital productivity spillovers from a country's nearest seven import partners, which begs the question: Why might we observe positive labour productivity spillovers and negative capital productivity spillovers? The negative capital productivity spillovers may indicate that a country's exports will fall if, on average, the capital stock of its seven nearest import partners rises. The positive labour productivity spillovers, on the other hand, may reflect

\footnotetext{
${ }^{17}$ The fitted local spatial stochastic frontier models which are not reported are available from the corresponding author upon request.
} 
the opportunity for a country to export more when, on average, the labour force of its seven nearest import partners increases.

\subsubsection{Efficiency Scores}

A TE score of 1 would place a country on the best practice production frontier and indicate that the country's output is as high as possible given its inputs. In the following analysis of the efficiency scores from the non-spatial and local spatial frontier models we place the emphasis on comparing the base set of efficiencies from the non-spatial model with those from our preferred $\mathbf{W}_{7 \text { Near }}$ model. In Appendix 3 we present the average efficiency scores for the 40 countries from the non-spatial model and our preferred $\mathbf{W}_{7 N e a r}$ model, as well as those from four other local spatial models for illustrative purposes.

The efficiency results for the non-spatial model and the $\mathbf{W}_{7 \text { Near }}$ model are similar. From Appendix 3 we can see that the average country efficiency and the standard deviation of the efficiencies for the non-spatial model are 0.607 and 0.244 , respectively. These are very similar to the average country efficiency of 0.576 and the standard deviation of the efficiencies of 0.266 from the $\mathbf{W}_{7 N e a r}$ model. The similarity between the average efficiencies and the average efficiency rankings from the non-spatial model and the $\mathbf{W}_{7 N e a r}$ model is evident because the Pearson correlation and the Spearman Rank correlation are in both cases around 0.97. This suggests that, on average, there is only a negligible amount of upward bias in mean efficiency from the non-spatial model vis-à-vis the $\mathbf{W}_{7 N e a r}$ model. However, it will become apparent in due course that even though the efficiency results from the non-spatial model and the $\mathbf{W}_{7 \text { Near }}$ model are similar, the two efficiency variables have very different effects on per capita $N O_{x}$ and $S O_{x}$ emissions in the Stage 2 models.

The above cursory glance in 5.1.1 at the average efficiency scores for individual countries from the non-spatial model and the $\mathbf{W}_{7 \text { Near }}$ model suggests that the efficiency estimates are reasonable. We reached this conclusion because for both the non-spatial model and the $\mathbf{W}_{7 \text { Near }}$ model, on average, the five most efficient countries are from Northern and Western Europe and the five least efficient countries are from Eastern Europe. We would expect these countries to be at the top and bottom of the efficiency rankings because of their geographical location and they have mean real income per capita in the top and bottom thirds of the sample.

Looking now at the time profiles of the mean efficiencies for EU and non-EU countries from the base non-spatial model and the $\mathbf{W}_{7 \text { Near }}$ model in panels (i) and (ii) of Figure 2. There are two striking features of Fig 2 (i) and Fig 2 (ii). Firstly, for both the non-spatial model and the $\mathbf{W}_{7 \text { Near }}$ model, the mean annual efficiency of EU countries is substantially larger than the mean annual efficiency for the non-EU cohort over the entire study period. Secondly, it is evident that the only noticeable change in the mean annual efficiencies for EU and non-EU countries from the non-spatial model and the $\mathbf{W}_{7 \text { Near }}$ model is due to the expansion of the EU in 2004 . Specifically, it is apparent that in 2004 there is a fall in the mean efficiency of EU countries and a smaller fall in the mean efficiency of non-EU countries. This suggests that, on average, the poor performance of the 2004 accession countries vis-à-vis their EU peers outweighs their high relative performance when they were in the non-EU cohort. This is particularly the case when we consider the implications of the 2004 enlargement for mean efficiency over the remainder of 
the sample. Our findings suggest that the 2004 enlargement resulted in a downward shift in the mean efficiency of EU countries, whereas the decline in the mean efficiency of non-EU countries appears to have been temporary.

[Insert Figure 2]

\subsubsection{TFP Growth}

Annual efficiency change, annual technical change and annual scale change are obtained for each country from the fitted non-spatial and local spatial translog production frontiers using Eq. 2 and our summed to obtain annual TFPG. To provide an insight into the TFPG variables which are used as a regressors in the Stage 2 models, in panels (i) and (ii) of Figure 3 we present average annual TFPG from: (i) the base non-spatial frontier model and (ii) the preferred $\mathbf{W}_{7 N e a r}$ frontier model. We also present the three constituent parts of average annual TFPG. In Figure 3 a value of 1.0 for the TFP index or either of its three constituent parts indicates that the annual growth rate is zero.

\section{[Insert Figure 3]}

It is apparent from Figure 3 that the corresponding estimates of $T F P G$, scale change, technical change and efficiency change from the non-spatial model and the $\mathbf{W}_{7 N e a r}$ model have similar, or at the very least broadly similar, time profiles. In addition, in both cases in Figure 3 scale change is the principal driver of TFPG. We also posit that the rather large estimates of TFPG in the first few years of the sample in Figure 3 are because $T F P G$ in the early years of the study period is highly dependent on the initial conditions. Given it is the estimates of the scale change component of TFPG in the first few years which are high this is most probably an adjustment to the assumption about the value of real capital stock in the first year of the sample. ${ }^{18}$ Over the study period TFPG will be progressively less dependent on the initial conditions. This is evident from Figure 3 for our preferred $\mathbf{W}_{7 \text { Near }}$ model where we can see from $2000-01$ through to the end of the study period, the estimates of TFPG are much more reasonable at just over $10 \%$.

\subsection{Elasticities from the Spatial Lag Models in Stage 2}

In Table 3 we present the estimation results for ten Stage 2 models. The distinction between the models in Table 3 is in terms of the dependent variable $\left(N O_{x} /\right.$ Pop or $S O_{x} /$ Pop $)$ and/or the specification of the model. The specification of the reported models in Table 3 is provided in parentheses, where the first element in parentheses denotes whether a non-spatial (NSp) or spatial (Sp) specification is used for the Stage 2 model and the second element denotes the Stage 1 model from which the TE and TFPG regressors are obtained.

\section{[Insert Table 3]}

\footnotetext{
${ }^{18}$ It was noted in footnote 10 above that the assumption about the value of real capital stock in the first year of the sample yields reasonable estimates of the capital elasticities at the sample mean for the non-spatial and local spatial frontier models. This assumption about the initial value of real capital stock, however, is not the conventional approach to obtain a starting value for the stock and was made because of data availability issues.
} 
Our preferred specification of the Stage 2 models is a pooled model. This is because we estimated models 5 and 6 in Table 3, which do not include TE and TFPG as regressors, using pooled data and introduced FEs and REs in successive models. For the pooled models: (i) the (in)direct $R G D P / P o p$ elasticities are significant and positive; (ii) the (in)direct $(R G D P / P o p)^{2}$ parameters are negative and significant; and (iii) the (in)direct $R G D P / P o p$ effect is larger than the (in)direct $(R G D P / P o p)^{2}$ effect. (i)-(iii) constitutes evidence of an (in)direct EKC. A direct $\mathrm{EKC}$, or in the parlance of a non-spatial model an own EKC, refers to the well-established inverted U-shaped relationship between a country's $R G D P / P o p$ and its $N O_{x} / P o p$ or $S O_{x} / P o p$. A indirect $\mathrm{EKC}$ is a new contribution and although not core to this paper is a feature of spatial pollution models which contain the spatial lag variable. A indirect EKC using, for example, the first way of calculating the indirect marginal effects which was discussed above is an inverted U-shaped relationship between $R G D P / P o p$ for the other countries in the sample and a country's $N O_{x} / P o p$ or $S O_{x} / P o p$. The FEs and REs specifications of models 5 and 6 , however, do not yield a complete set of significant direct and indirect $R G D P / P o p$ and $(R G D P / P o p)^{2}$ elasticities. This suggests that the FEs and REs are capturing latent heterogeneity which is embodied in $R G D P / P o p$ or $(R G D P / P o p)^{2}{ }^{19}$ For this reason we prefer the pooled spatial lag specification of the Stage 2 models. We also explored including $(R G D P / P o p)^{3}$ as an additional independent variable because of the possibility of a further turning point. When this variable was added to models 5 and 6 in Table 3, the direct and indirect $(R G D P / P o p)^{3}$ effects were a long way from being significant so this variable was omitted. To facilitate comparisons between models $(R G D P / P o p)^{3}$ was not included in any other model specifications.

Our preferred Stage 2 specifications for $N O_{x} / P o p$ and $S O_{x} / P o p$ are models 9 and 10, respectively. This is for two reasons. Firstly, we prefer the $\mathbf{W}_{7 N e a r}$ stochastic frontier model in Stage 1 so the preferred Stage 2 specification is therefore one where the TE and TFPG independent variables are from the $\mathbf{W}_{7 N e a r}$ Stage 1 model. Secondly, we can see from the reported results for models 9 and 10 that in both cases the $\delta$ coefficient is significant at the $1 \%$ level or lower, which justifies a spatial lag specification rather than models $1-4$, which are all non-spatial specifications. Accordingly, in this discussion of the Stage 2 results we focus on models 9 and 10 and in particular the results for TE and TFPG as they represent the principal empirical contribution of the paper. The estimation results for the other eight non-spatial and spatial Stage 2 models are reported and touched on in the discussion for reasons of comparison. We note that $\delta$ cannot be interpreted as an elasticity which is why we calculate the direct, indirect and total elasticities. That said, the estimates of $\delta$ can be used to indicate the degree of spatial dependence. The estimate of $\delta$ in model 10 is just over twice the estimate in model 9, which indicates that $S O_{x} / P o p$ is much more spatially dependent than $N O_{x} / P o p$, which is what we would expect to find.

In models 3 and 4, which are the non-spatial counterparts of models 9 and 10, the own coefficients on the TFPG and TE variables are non-negligible and significant at the $1 \%$ level or lower. The estimation results for models 9 and 10 for $T E$ are at odds with those for models 3 and 4 and thus justify the spatial lag specification. This is because the direct $T E$ coefficients in models

\footnotetext{
${ }^{19}$ When the FEs and REs are correlated with variables like this, the estimated parameters can be biased and inconsistent.
} 
9 and 10 are a long way from being significant. To put the implications of the own/direct, indirect and total TFPG and TE elasticities from models 3, 4, 9 and 10 which are significant at the 5\% level or lower into context, let us consider the changes in TFPG and TE in an average country and on average across the other countries in the sample to reduce $N O_{x} / P o p$ and $S O_{x} /$ Pop by $10 \%$ in a country. The implications are quite dramatic because from model 3 we can conclude that to reduce $N O_{x} /$ Pop by, on average, $10 \%$ for a European country, the country's TF PG must fall by $8.26 \%$ or the country's $T E$ must fall by $13.51 \% .{ }^{20}$ In contrast, for model 9 a reduction of $N O_{x} /$ Pop by, on average, $10 \%$ for a European country would require a much smaller fall in the country's TFPG if there was a fall in TFPG across Europe. This is because, unlike model 3, in model 9 a country's $N O_{x} /$ Pop does not just fall because its TFPG has fallen but also because the TFPG spillovers which come from other countries in the sample fall, where the latter follows automatically from a spatial lag specification if there is a fall in TFPG across Europe. To illustrate, from panel (i) of Table 4 we can see for model 9 , which is the $\left(\mathrm{Sp}-W_{7 N e a r}\right)$ specification in Table 4, that a reduction in $N O_{x} / P o p$ by, on average, $10 \%$ for a European country would require only a $5.83 \%$ fall in the country's TFPG and a $1.41 \%$ decline in TFPG spillovers coming to the country from other countries. ${ }^{21}$

\section{[Insert Table 4]}

Model 4 in Table 3 predicts that to reduce $S O_{x} / P o p$ by, on average, $10 \%$ for a European country, the country's TFPG must fall by $3.83 \%$ or the country's TE must fall by $5.62 \%$. From model 10, however, a reduction of $S O_{x} /$ Pop by, on average, $10 \%$ for a European country would require a much smaller fall in the country's TFPG if there was a fall in TFPG across Europe. This is evident because from panel (ii) of Table 4 , the results for the $\left(\mathrm{Sp}-W_{7 N e a r}\right)$ model indicate that a reduction in $S O_{x} / P o p$ by, on average, $10 \%$ for a European country would require only a $2.04 \%$ fall in the country's TFPG and a $1.32 \%$ decline in TFPG spillovers coming to the country from other countries. Furthermore, as comparators Table 4 also contains the declines in direct, indirect and total TFPG or TE for some of the other Stage 2 spatial lag models to reduce $N O_{x} /$ Pop or $S O_{x} /$ Pop by, on average, $10 \%$ in a country.

As noted in the opening section of this paper, Førsund and Hjalmarsson (1988) point out the implications of the choice of technology in energy intensive industries for long run technical change, where technical change is a key factor affecting energy usage and thus emissions. From our preferred $\left(\mathrm{Sp}-W_{7 N e a r}\right)$ specification of the Stage 2 models for $N O_{x} / P o p$ and $S O_{x} / P o p$ we find for both pollutants that a country's TFPG must fall to achieve further reductions in per capita emissions. This implies that the easiest reductions in emissions from using newer capital which also leads to a rise in TFPG have already been taken advantage of. This stands to reason because $N O_{x}$ and $S O_{x}$ emissions in the EU have been tightly regulated for a long period of time. The development and diffusion of greener technology will therefore be key to further reductions in $N O_{x} /$ Pop and $S O_{x} /$ Pop. More specifically, renewable energy technology, which Førsund and

\footnotetext{
${ }^{20} \frac{-10.00}{1.21}=-8.26$ and $\frac{-10.00}{0.74}=-13.51$, where 1.21 and 0.74 are the significant own TFPG and TE parameters, respectively, from model 3 .

$21 \frac{-10.00}{1.381}=-7.24$, where 1.381 is the significant total TFPG parameter from model 9 . Then $-7.24 \times \frac{1.112}{1.381}=$ -5.83 and $-7.24+5.83=-1.41$, where 1.112 is the significant direct TFPG parameter from model 9 .
} 
Hjalmarsson (2011) focus on in their very recent work, will evidently have a big role to play in further reductions of $N O_{x} / P o p$ and $S O_{x} / P o p$.

Finally, since the principal empirical contribution of this paper are the direct, indirect and total TFPG and TE elasticities from the spatial lag models for $N O_{x} / P o p$ and $S O_{x} / P o p$, we only discuss the elasticities for some of the other variables very briefly. One striking feature of the direct and indirect elasticities for other variables is that the direct Trade_Share and direct Ind_Share elasticities differ between the $\left(\mathrm{Sp}-W_{7 N e a r}\right)$ models for $N O_{x} / P o p$ and $S O_{x} / P o p$. This is evident because the direct Trade_Share elasticity from the $\left(\mathrm{Sp}-W_{7 N e a r}\right)$ model for $N O_{x} / P o p$ is not significant but in the corresponding model for $S O_{x} /$ Pop, the direct Trade_Share elasticity is significant at the $1 \%$ level taking a value of 0.29 . Conversely, the direct Ind_Share elasticity from the $\left(\mathrm{Sp}-W_{7 N e a r}\right)$ model for $S O_{x} /$ Pop is not significant, whereas this elasticity from the $\left(\mathrm{Sp}-W_{7 N e a r}\right)$ model for $N O_{x} / P o p$ is significant at the $5 \%$ level taking a value of 0.47 .

\section{Concluding Remarks}

It is usual in the DEA and SFA literature where there is a negative externality associated with production to jointly model the negative externality and the production of marketed output using a distance function. By including the negative externality in the production technology, the externality influences productive performance (i.e. efficiency and TFP growth). We, however, have drawn on theoretical work from the environmental economics literature which posits that TFP influences environmental quality to suggest an alternative way of using efficiency and productivity techniques to model pollution. Rather than use a single stage approach by incorporating emissions into an input-oriented or multiple output-oriented specification of the technology we adopted a two-stage approach. In Stage 1 we omitted emissions from the technology so that per capita emissions could be the dependent variable in the Stage 2 models. Furthermore, in our empirical analysis we modified the approach used in the theoretical environmental economics literature by using two measures of productive performance (technical efficiency and TFP growth) as determinants in the Stage 2 models of per capita emissions.

A feature of Stages 1 and 2 of the analysis is the modelling of the cross-sectional spatial dependence. In Stage 1 we make a contribution to the fledgling literature on spatial SFA by proposing a stochastic frontier framework which accounts for local spatial dependence (i.e. first order neighbour effects). We accounted for local spatial dependence by introducing spatial lags of the independent variables as additional variables which shift the frontier technology. As we have highlighted above these local spatial variables are not endogenous so the local spatial stochastic frontier framework that we propose can easily be applied more widely as it can be estimated using standard ML procedures. Moreover, in the empirical application in Stage 1 to aggregate production of European countries, the LR test results and values of the AIC and BIC all suggest that the eleven local spatial stochastic frontier models are preferred to the non-spatial model. The AIC and BIC were also used to identify a preferred local spatial stochastic frontier model. In contrast, the Stage 2 spatial models contain a spatial lag of the dependent variable and therefore differ from the Stage 1 models as they take account of global spatial dependence in the cross- 
sections (i.e. first order through to $(N-1)$ th order neighbour effects).

Finally, we note that our findings on the effect of TFP growth on per capita $N O_{x}$ and $S O_{x}$ emissions from the preferred Stage 2 spatial models are interesting from a methodological perspective and also a policy perspective. In brief, from our preferred Stage 2 spatial models and the corresponding non-spatial models we find that a country's TFP growth must fall to reduce its per capita $N O_{x}$ or $S O_{x}$ emissions. For both pollutants, to achieve a pre-specified reduction in per capita emissions, our preferred spatial models suggest that the fall in a country's TFP growth is smaller than that from the corresponding non-spatial model. This is because in the Stage 2 spatial models, some of the fall in a country's per capita emissions is due to a fall in TFP growth spillovers coming to the country which is overlooked in the non-spatial specification.

\section{References}

Anselin, L. (2001): 'Spatial effects in econometric practice in environmental and resource economics'.American Journal of Agricultural Economics, Vol. 83, pp. 705-710.

Atkinson, S. E., and J. H. Dorfman (2005): 'Bayesian measurement of productivity and efficiency in the presence of undesirable outputs: Crediting electric utilities for reducing air pollution'. Journal of Econometrics, Vol. 126, pp. 445-468.

Badunenko, O., D. J. Henderson and V. Zelenyuk (2008): 'Technological change and transition: Relative contributions to worldwide growth during the 1990s'. Oxford Bulletin of Economics and Statistics, Vol. 70, pp. 461-492.

Baltagi, B. H., J. M. Griffin and W. Xiong (2000): 'To pool or not to pool: Homogenous versus heterogenous estimators applied to cigarette demand'. Review of Economics and Statistics, Vol. 82, pp. 117-126.

Baltagi, B. H., AND D. Levin (1986): 'Estimating dynamic demand for cigarettes using panel data: The effects of bootlegging, taxation and advertising reconsidered'. Review of Economics and Statistics, Vol. 68, pp. 148-155.

Battese, G. E., And T. J. Coelli (1992): 'Frontier production functions, technical efficiency and panel data: With application to paddy farmers in India'. Journal of Productivity Analysis, Vol. 3, pp. 153-169.

Burnside, C., M. Eichenbaum and S. Rebelo (1995): Capital utilization and returns to scale. In the NBER Macroeconomics Annual 1995, Volume 10, Bernanke, B. S. and J. J. Rotemberg (Eds). Cambridge, MA: MIT Press.

Carson, R. T. (2010): 'The environmental Kuznets curve: Seeking empirical regularity and theoretical structure'. Review of Environmental Economics and Policy, Vol. 4, pp. 3-23.

CAsu, B., ANd C. Giradone (2009): 'Testing the relationship between competition and efficiency in banking: A panel data analysis'. Economics Letters, Vol. 105, pp. 134-137.

Caves, D. W., L. R. Christensen and W. E. Diewert (1982): 'The economic theory of index numbers and the measurement of input, output and productivity'. Econometrica, Vol. 50, pp. 1393-1414.

Chimeli, A. B. (2007): 'Growth and the environment: Are we looking at the right data?'. Economics Letters, Vol. 96, pp. 89-96.

Chimeli, A. B., And J. B. Braden (2005): 'Total factor productivity and the environmental Kuznets curve'. Journal of Environmental Economics and Management, Vol. 49, pp. 366-380.

Cipollini, A., And F. Fiordelisi (2012): 'Economic value, competition and financial distress in the European banking system'. Journal of Banking and Finance, Vol. 36, pp. 3101-3109.

Coelli, T., A. Estache, S. Perelman and L. Trujillo (2003): 'A primer on efficiency measurement for utilities and transport regulators'. Washington, DC: World Bank Institute.

Cole, M. A. (2007): 'Corruption, income and the environment: An empirical analysis'. Ecological Economics, Vol. 62, pp. 637-647.

Cornwell, C., P. Schmidt and R. C. Sickles (1990): 'Production frontiers with cross-sectional and time-series variation in efficiency levels'. Journal of Econometrics, Vol. 46, pp. 185-200.

Cuesta, R. A., C. A. K. Lovell and J. L. Zofio (2009): 'Environmental efficiency measurement with translog distance functions: A parametric approach'. Ecological Economics, Vol. 68, pp. 2232-2242.

Druska, V., AND W. C. Horrace (2004): 'Generalized moments estimation for spatial panel data: Indonesian rice farming'. American Journal of Agricultural Economics, Vol. 86, pp. 185-198.

Elhorst, J. P. (2012): 'MATLAB software for spatial panels'. Forthcoming in the International Regional Science Review.

Elhorst, J. P. (2009): Spatial panel data models. In the Handbook of Applied Spatial Analysis, Fischer M. M., and A. Getis (Eds). Berlin/Heidelberg/New York: Springer. 
Färe, R., S. Grosskopf, C. A. K. Lovell and C. Pasurka (1989): 'Multilateral productivity comparisons when some outputs are undesirable: A nonparametric approach'. Review of Economics and Statistics, Vol. 71, pp. 90-98.

FÄre, R., S. Grosskopf And D. TytecA (1996): 'An activity analysis model of the environmental performance of firms- application to fossil-fuel-fired electric utilities'. Ecological Economics, Vol. 18, pp. 161-175.

Fernández, C., G. Koop And M. F. J. Steel (2005): 'Alternative efficiency measures for multiple-output production'. Journal of Econometrics, Vol. 126, pp. 411-444.

Førsund, F., AND L. HJalmarsson (2011): 'Renewable energy expansion and the value of balance regulation power'. In Johansen, P-O., and B. Kriström (Eds): Modern Cost-Benefit Analysis of Hydropower Conflicts. Cheltenham, UK: Edward Elgar.

Førsund, F., And L. HJalmarsson (1988): 'Choice of technology and long-run technical change in energyintensive industries'. Energy Journal, Vol. 9, pp. 79-97.

Frankel, J. (2009): 'Environmental effects of international trade'. John F. Kennedy School of Government, Harvard University, Research Working Paper 09-006.

Glass, A. J., K. Kenjegalieva And R. C. Sickles (2014): 'Estimating efficiency spillovers with state level evidence for manufacturing in the US'. Economics Letters, Vol. 123, pp. 154-159.

Glass, A. J., K. Kenjegalieva and R. C. Sickles (2013a): 'How efficiently do U.S. cities manage roadway congestion?'. Journal of Productivity Analysis, Vol. 40, pp. 407-428.

Glass, A. J., K. Kenjegalieva And J. Paez-Farrell (2013b): 'Productivity growth decomposition using a spatial autoregressive frontier model'. Economics Letters, Vol. 119, pp. 291-295.

Hernandez-Sancho, F., A. Pichzo-Tadeo And E. Reig-Martinez (2000): 'Efficiency and environmental regulation- an application to Spanish wooden goods and furnishings industry'. Environmental and Resource Economics, Vol. 15, pp. 365-378.

Heston, A., R. Summers And B. Aten (2011): Penn World Table Version 7.0. Center for International Comparisons of Production, Income and Prices, University of Pennsylvania.

Ireland, P. N. (2004): 'A method for taking models to data'. Journal of Economic Dynamics and Control, Vol. 28, pp. 1205-1226.

Ivanova, K. (2011): 'Corruption and air pollution in Europe'. Oxford Economic Papers, Vol. 63, pp. 49-70.

Johnson, S., W. Larson, C. Papageorgiou and A. Subramanian (2013): 'Is newer better? Penn World Table revisions and their impact on growth estimates'. Journal of Monetary Economics, vol. 60, pp. 255-274.

Kelejian, H. H., And I. R. Prucha (2010): 'Specification and estimation of spatial autoregressive models with autoregressive and heteroskedastic disturbances'. Journal of Econometrics, Vol. 157, pp. 53-67.

Kelejian, H. H., AND I. R. PRUCha (1999): 'A generalized moments estimator for the autoregressive parameter in a spatial model'. International Economic Review, Vol. 40, pp. 509-533.

Kelejian, H. H., And I. R. PRuCha (1998): 'A generalized spatial two stage least squares procedure for estimating a spatial autoregressive model with autoregressive disturbances'. Journal of Real Estate Finance and Economics, Vol. 17, pp. 99-121.

Koop, G., And L. Tole (2008): 'What is the environmental performance of firms overseas?: An empirical investigation of the global gold mining industry'. Journal of Productivity Analysis, Vol. 30, pp. 129-143.

LeSage, J., And R. K. PACE (2009): Introduction to Spatial Econometrics. Boca Raton, Florida: CRC Press, Taylor \& Francis Group.

Maddison, D. (2007): 'Modelling sulphur emissions in Europe: A spatial econometric approach'. Oxford Economic Papers, Vol. 59, pp. 726-743.

Maddison, D. (2006): 'Environmental Kuznets curves: A spatial econometric approach'. Journal of Environmental Economics and Management, Vol. 51, pp. 218-230.

Murdoch, J. C., And T. SAndler (1997): 'The voluntary provision of a pure public good: The case of reduced CFC emissions and the Montreal Protocol'. Journal of Public Economics, Vol. 63, pp. 331-349.

Murdoch, J. C., T. Sandler And K. Sargent (1997): 'A tale of two collectives: Sulphur versus nitrogen oxides emission reduction in Europe'. Economica, Vol. 64, pp. 281-301.

Neyman, J. And E. L. Scott (1948): 'Consistent estimates based on partially consistent observations'. Econometrica, Vol. 16, pp. 1-32.

OREA, L. (2002): 'Parametric decomposition of a generalized Malmquist productivity index'. Journal of Productivity Analysis, Vol. 18, pp. 5-22.

Pfaffermayr, M. (2013): 'The Cliff and Ord test for spatial correlation of the disturbances in unbalanced panel models'. International Regional Science Review, Vol. 36, pp. 492-506.

Pfaffermayr, M. (2009): 'Conditional $\beta$ - and $\sigma$-convergence in space: A maximum likelihood approach'. Regional Science and Urban Economics, Vol. 39, pp. 63-78.

Pope III, C. A, M. J. Thun, M. M. Namboodiri, D. W. Dockery, J. S. Evans, F. E. Speizer And C. W. HeAth JR (1995): 'Particulate air pollution as a predictor of mortality in a prospective study of US adults'. American Journal of Respiratory Critical Care Medicine, Vol. 151, pp. 669-674.

Reinhard, S., C. A. K. Lovell and G. J. Thijssen (2000): 'Environmental efficiency with multiple environmentally detrimental variables; estimated with SFA and DEA'. European Journal of Operational Research, Vol. 121, pp. 287-303. 
Reinhard, S., C. A. K. Lovell and G. J. Thijssen (1999): 'Econometric estimation of technical and environmental efficiency: An application to Dutch dairy farms'. American Journal of Agricultural Economics, Vol. 81, pp. 44-60.

SAal, D. S., D. PARker And T. Weyman-Jones (2007): 'Determining the contribution of technical change, efficiency change and scale change to productivity growth in the privatized English and Welsh water and sewerage industry: 1985-2000'. Journal of Productivity Analysis, Vol. 28, pp. 127-139.

Schmidt, P., And R. C. Sickles (1984): 'Production frontiers and panel data'. Journal of Business and Economic Statistics, Vol. 2, pp. 367-374.

Smets, F. And R. Wouters (2003): 'An estimated dynamic stochastic general equilibrium model of the euro area'. Journal of the European Economic Association, Vol. 1, pp. 1123-1175.

Stern, D. I., And R. K. Kaufmann (2000): 'Detecting a global warming signal in hemispheric temperature series: A structural time series analysis'. Climatic Change, Vol. 47, pp. 411-438.

Stevenson, R. E. (1980): 'Likelihood functions for generalized stochastic frontier estimation'. Journal of Econometrics, Vol. 13, pp. 57-66.

TytecA, D. (1997): 'Linear programming models for the measurement of environmental performance of firmsconcepts and empirical results'. Journal of Productivity Analysis, Vol. 8, pp. 183-197.

Weber, W. L., AND B. R. Domazlicky (2001): 'Productivity growth and pollution in state manufacturing'. Review of Economics and Statistics, Vol. 83, pp. 195-199.

Wheelock, D. C., AND P. W. Wilson (2000): 'Why do banks disappear? The determinants of U.S. bank failures and acquisitions'. Review of Economics and Statistics, Vol. 82, pp. 127-138.

ZAIM, O., AND F. TASKIN (2000): 'A Kuznets curve in environmental efficiency: An application on OECD countries'. Environmental and Resource Economics, Vol. 17, pp. 21-36. 


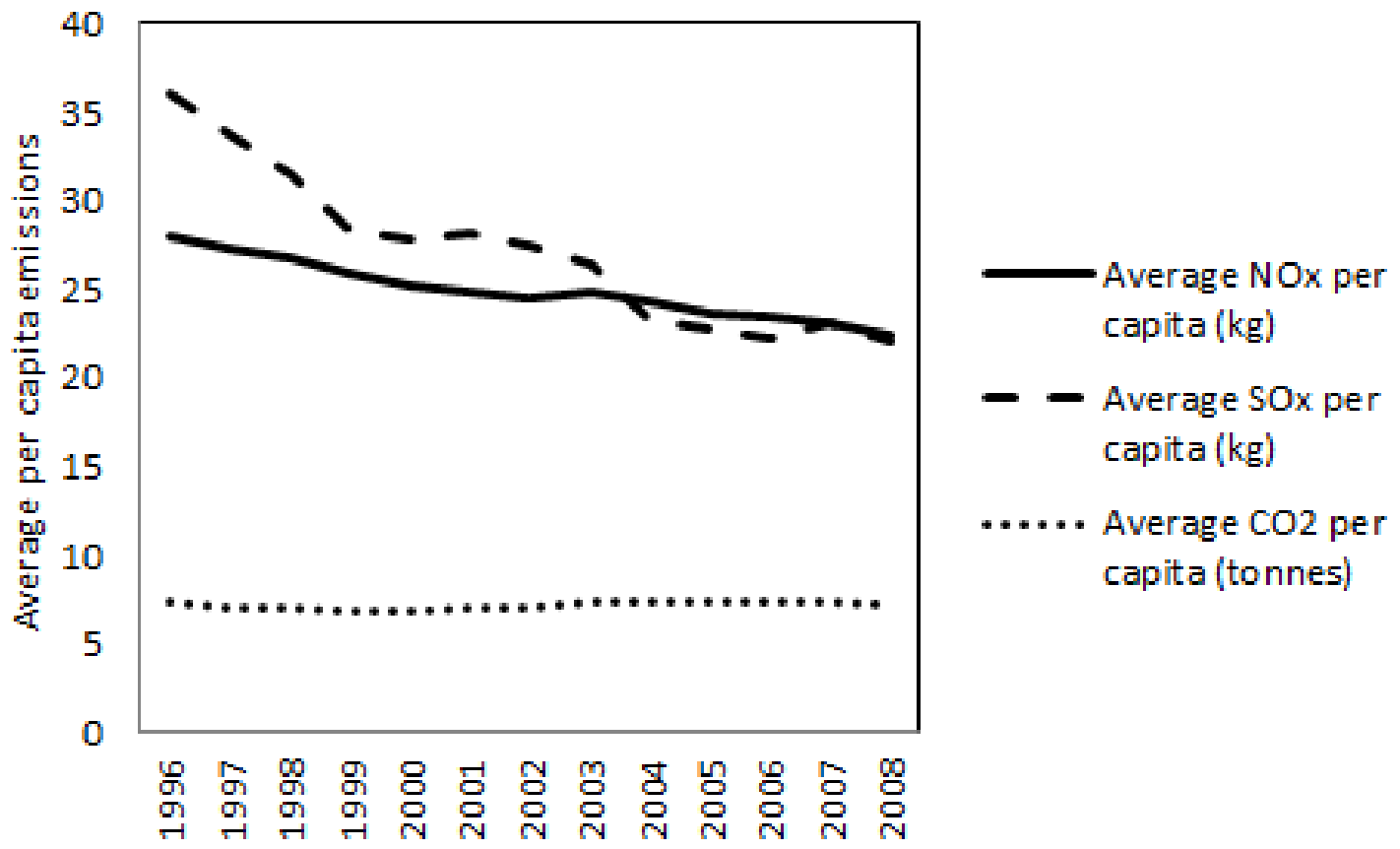

Figure 1: Average annual per capita emissions over the study period for Stage 2 
Fig 2 Panel (i): Base non-spatial

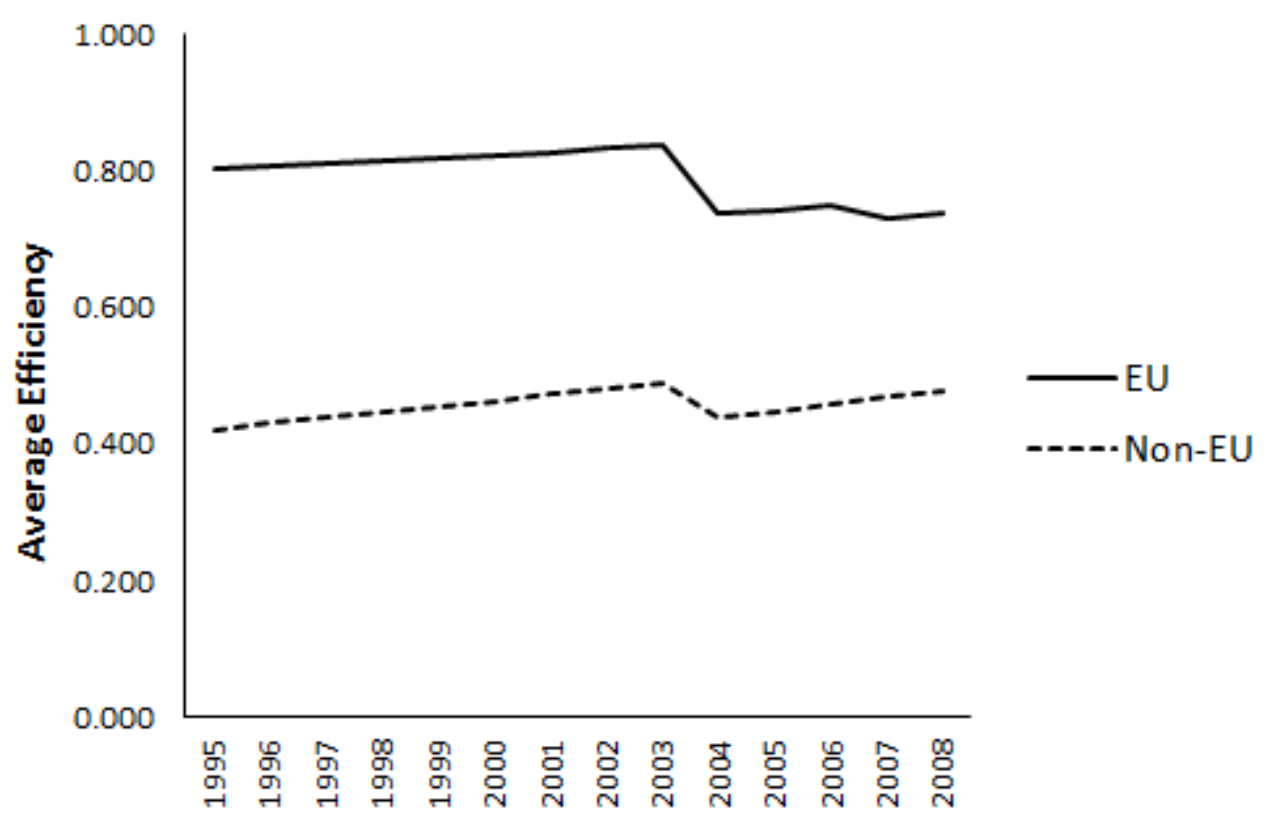

Fig 2 Panel (ii): $\mathbf{W}_{7 \text { Near }}$

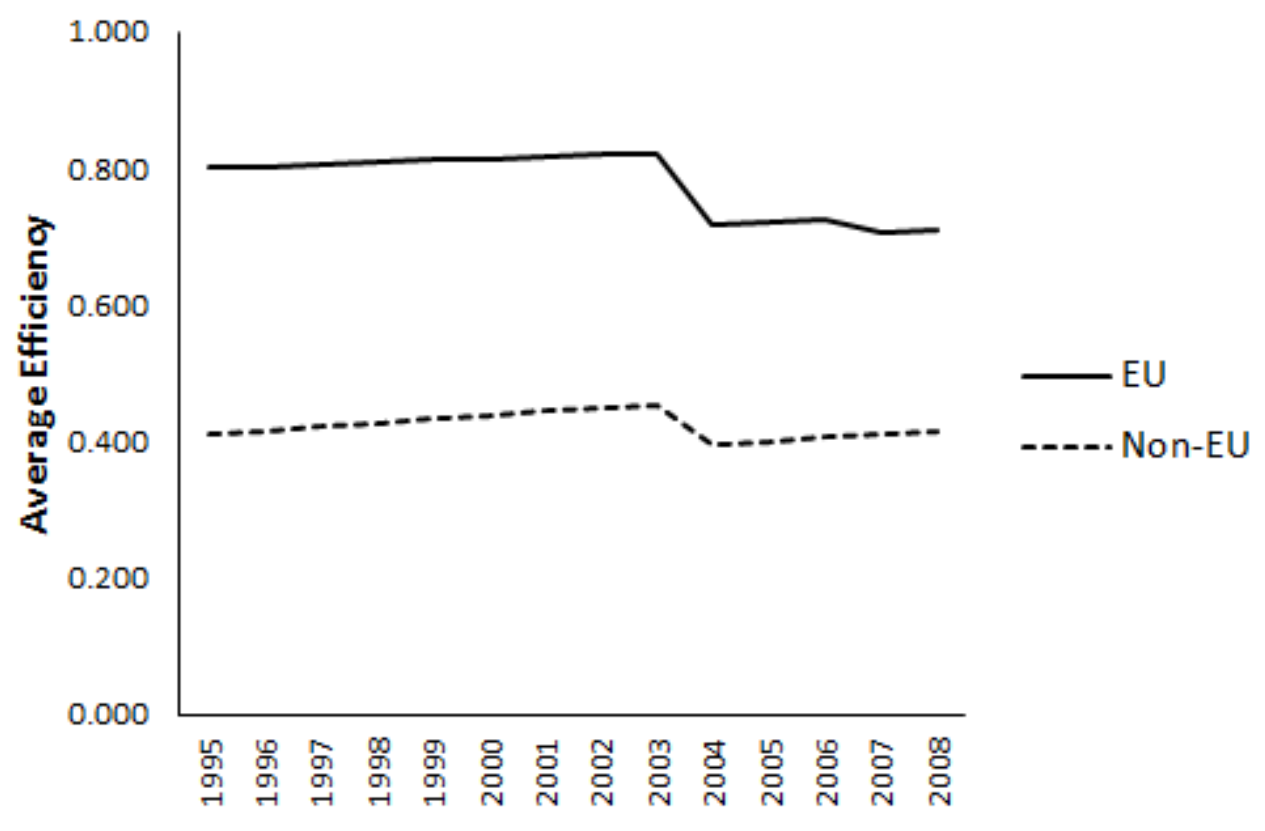

Figure 2: Annual mean efficiencies from the non-spatial model and the preferred local spatial model 


\section{Fig 3 Panel (i): Base non-spatial}

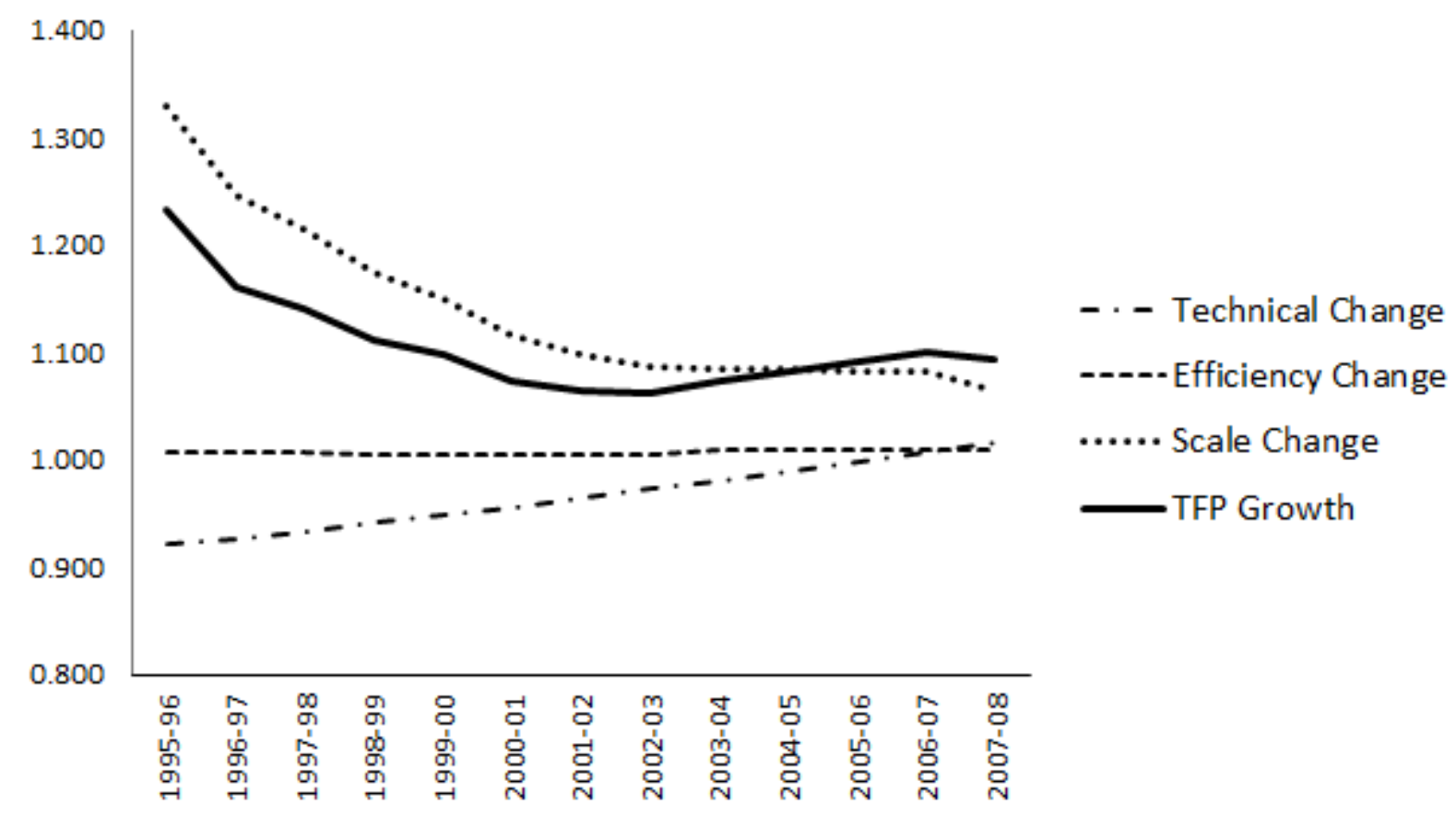

Fig 3 Panel (ii): $\mathbf{W}_{\mathbf{7 N e a r}}$

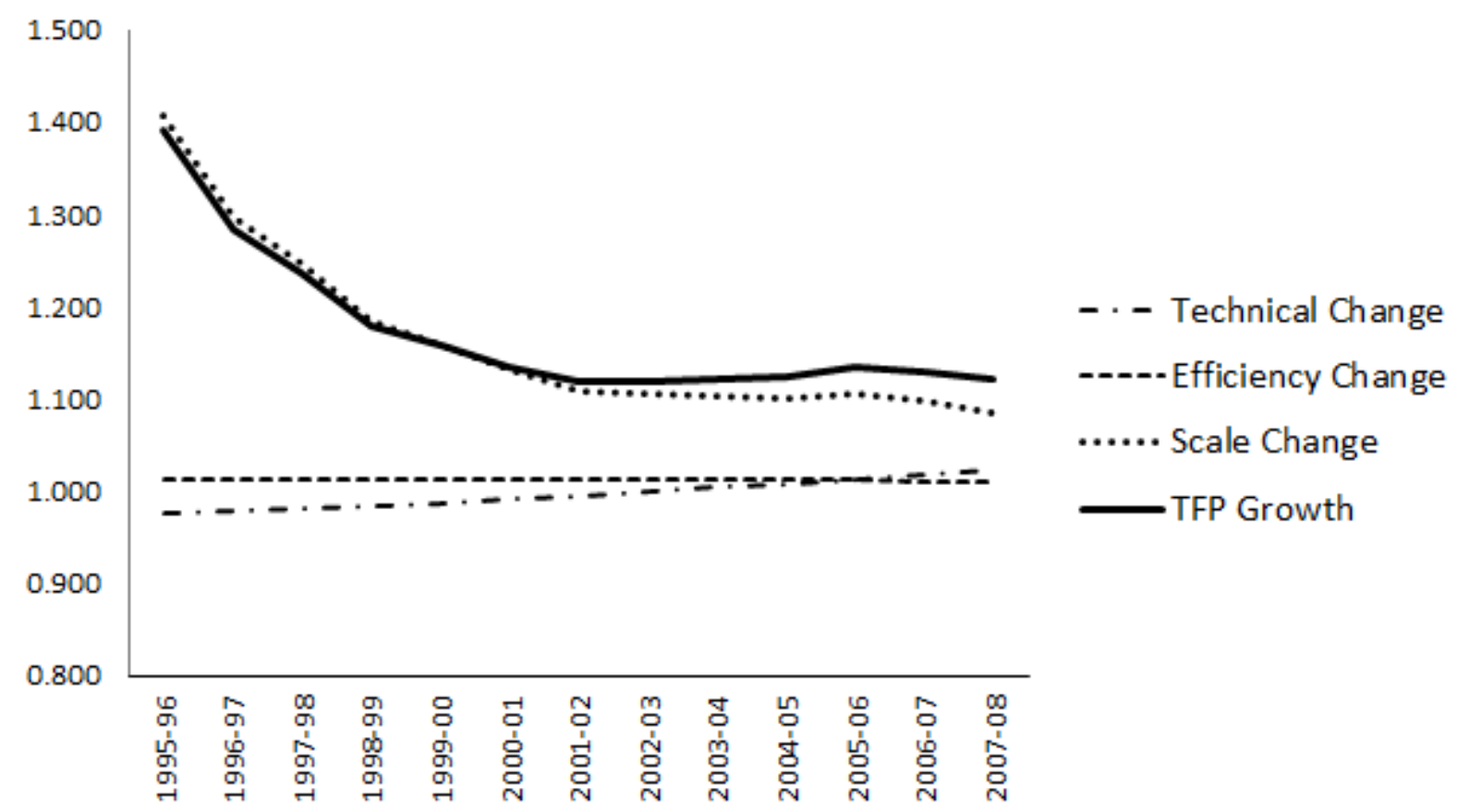

Figure 3: Average TFP growth decompositions from the non-spatial model and the preferred local spatial model 
Table 1: Summary statistics

\begin{tabular}{|c|c|c|c|c|c|}
\hline & Variable & Mean & St.Dev. & Min & Max \\
\hline \multicolumn{6}{|l|}{ Stage 1} \\
\hline Real GDP (millions) & $y$ & 391,000 & 618,000 & 5,877 & $2,800,000$ \\
\hline Labour $(000 \mathrm{~s})$ & $x_{1}$ & 9,338 & 14,212 & 139 & 75,730 \\
\hline Real capital stock (millions) Dep Rate $=6.0 \%$ & $x_{2}$ & 481,000 & 850,000 & 1,786 & $5,130,000$ \\
\hline Arable land as a share of total land & $z_{1}$ & 0.25 & 0.14 & 0.0006 & 0.57 \\
\hline $\begin{array}{l}\text { Sum of exports and imports as a share } \\
\text { of GDP }\end{array}$ & $z_{2}$ & 0.92 & 0.44 & 0.29 & 3.24 \\
\hline Government spending as a share of GDP & $z_{3}$ & 0.09 & 0.03 & 0.05 & 0.16 \\
\hline \multicolumn{6}{|l|}{ Stage 2} \\
\hline$N O_{x}$ emissions per capita $(\mathrm{Kg})$ & $\frac{N O_{x}}{P_{o p}}$ & 24.96 & 13.33 & 5.20 & 96.19 \\
\hline$S O_{x}$ emissions per capita $(\mathrm{Kg})$ & $\frac{S O_{x}}{P o p}$ & 27.13 & 30.45 & 1.72 & 243.06 \\
\hline Real GDP per capita (000s) & $\frac{R G D P}{P o p}$ & 20.94 & 14.15 & 1.47 & 89.81 \\
\hline $\begin{array}{l}\text { Value added by the industrial sector as } \\
\text { a share of GDP }\end{array}$ & Ind_Share & 0.30 & 0.08 & 0.14 & 0.70 \\
\hline $\begin{array}{l}\text { Sum of exports and imports as a share } \\
\text { of GDP }\end{array}$ & Trade_Share & 0.94 & 0.45 & 0.31 & 3.24 \\
\hline Technical Efficiency & $T E$ & $0.41-0.61$ & $0.21-0.27$ & $0.05-0.11$ & $0.98-0.99$ \\
\hline TFP Growth & $T F P G$ & $0.09-0.17$ & $0.05-0.09$ & $-0.06-0.02$ & $0.29-0.51$ \\
\hline
\end{tabular}




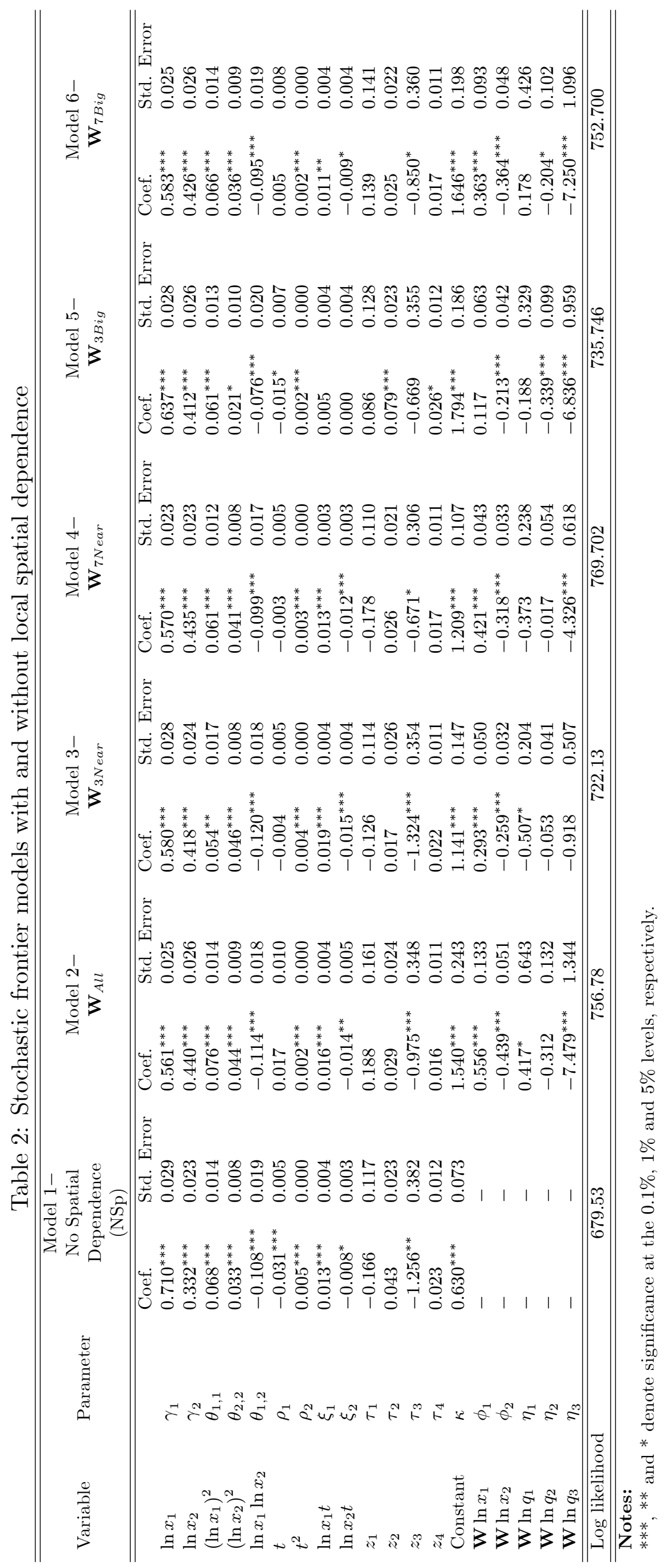




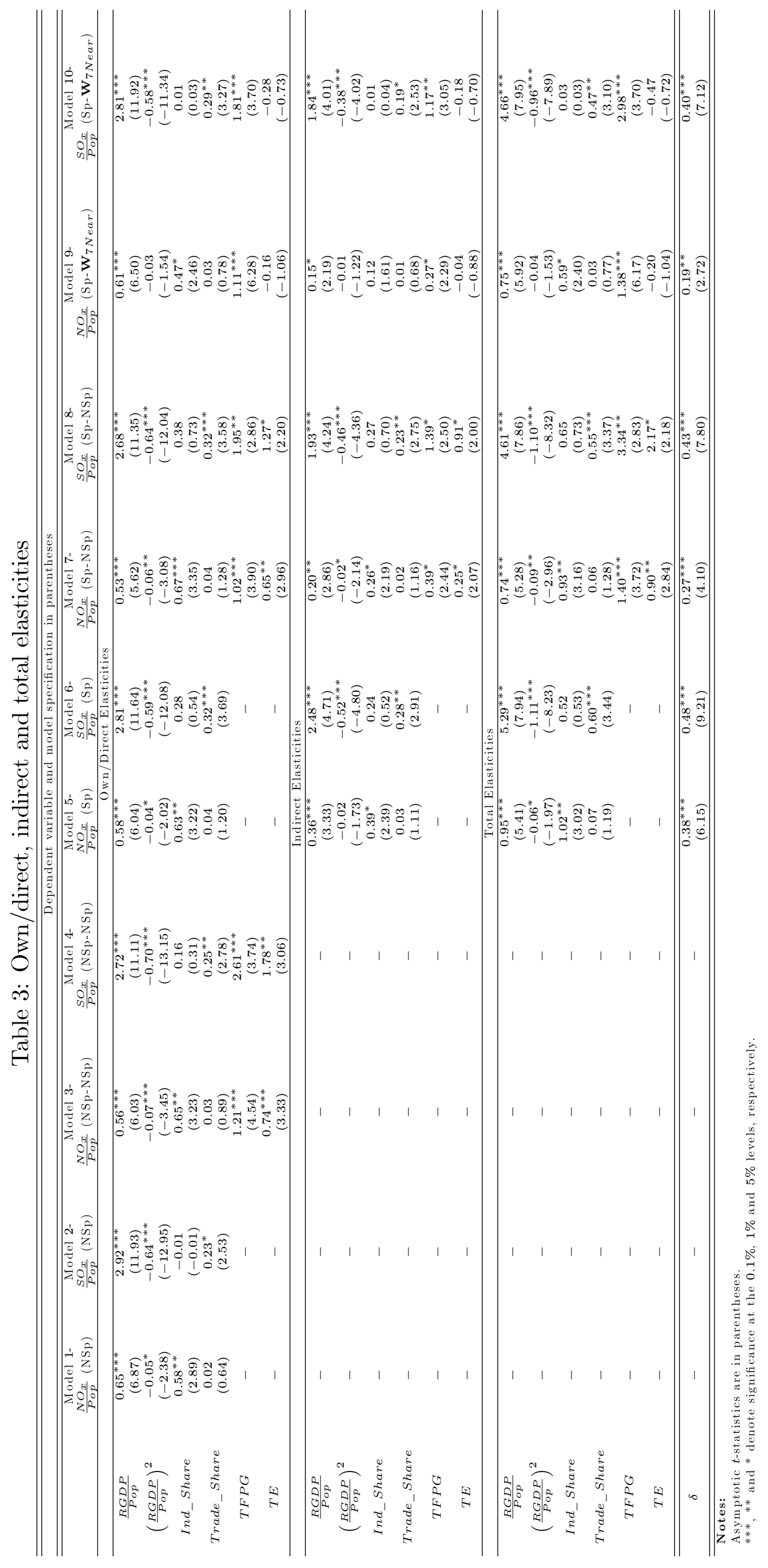


Table 4: Efficiency and TFP growth changes to cut per capita emissions by 10 per cent

\begin{tabular}{|c|c|c|c|c|c|c|}
\hline \multicolumn{7}{|c|}{ Panel i: $10 \%$ cut in per capita $\mathrm{NO}_{\mathrm{x}}$ emissions in an average European country } \\
\hline \multirow[t]{2}{*}{ Stage 2 Model } & \multicolumn{3}{|c|}{$\begin{array}{ll}\text { Efficiency } \\
\end{array}$} & \multicolumn{3}{|c|}{ TFP Growth } \\
\hline & Drect $(\%)$ & Indirect $(\%)$ & Total $(\%)$ & Direct $(\%)$ & Indirect $(\%)$ & Total $(\%)$ \\
\hline$S p-N S p$ & -8.07 & -3.09 & -11.16 & -5.16 & -1.97 & -7.13 \\
\hline$S p-\mathbf{W}_{A l l}$ & $N A$ & $N A$ & $N A$ & -6.84 & $N A$ & -7.82 \\
\hline$S p-\mathbf{W}_{3 N e a r}$ & $N A$ & $N A$ & $N A$ & -5.69 & -1.74 & -7.43 \\
\hline$S p-\mathbf{W}_{7 \text { Near }}$ & $N A$ & $N A$ & $N A$ & -5.83 & -1.41 & -7.24 \\
\hline$S p-\mathbf{W}_{3 B i g}$ & $N A$ & $N A$ & $N A$ & -5.14 & -1.52 & -6.66 \\
\hline$S p-\mathbf{W}_{7 B i g}$ & $N A$ & $N A$ & $N A$ & -6.29 & $N A$ & -7.40 \\
\hline \multicolumn{7}{|c|}{ Panel ii: $10 \%$ cut in per capita $\mathrm{SO}_{\mathrm{x}}$ emissions in an average European country } \\
\hline \multirow[t]{2}{*}{ Stage 2 Model } & \multicolumn{3}{|c|}{ Efficiency } & \multicolumn{3}{|c|}{ TFP Growth } \\
\hline & Direct $(\%)$ & Indirect $(\%)$ & Total $(\%)$ & Direct $(\%)$ & Indirect $(\%)$ & Total $(\%)$ \\
\hline$S p-N S p$ & -2.68 & -1.92 & -4.60 & -1.74 & -1.25 & -2.99 \\
\hline$S p-\mathbf{W}_{A l l}$ & $N A$ & $N A$ & $N A$ & -2.16 & -1.37 & -3.53 \\
\hline$S p-\mathbf{W}_{3 N e a r}$ & $N A$ & $N A$ & $N A$ & -2.12 & -1.40 & -3.52 \\
\hline$S p-\mathbf{W}_{7 N e a r}$ & $N A$ & $N A$ & $N A$ & -2.04 & -1.32 & -3.36 \\
\hline$S p-\mathbf{W}_{3 B i g}$ & $N A$ & $N A$ & $N A$ & -1.61 & -1.18 & -2.79 \\
\hline$S p-\mathbf{W}_{7 B i g}$ & -2.69 & -1.47 & -4.16 & -2.36 & -1.28 & -3.64 \\
\hline
\end{tabular}

Note: $N A$ is used to denote where the corresponding parameter is not significant at the $5 \%$ level or lower. 
Appendix 1: Countries in the sample

$\begin{array}{llll}\text { Albania } & \text { Denmark } & \text { Latvia } & \text { Romania } \\ \text { Armenia } & \text { Estonia } & \text { Lithuania } & \text { Russia } \\ \text { Austria } & \text { Finland } & \text { Luxembourg } & \text { Slovakia } \\ \text { Azerbaijan } & \text { France } & \text { Macedonia } & \text { Slovenia } \\ \text { Belarus } & \text { Germany } & \text { Malta } & \text { Spain } \\ \text { Belgium } & \text { Greece } & \text { Moldova } & \text { Sweden } \\ \text { Bulgaria } & \text { Hungary } & \text { Netherlands } & \text { Switzerland } \\ \text { Croatia } & \text { Iceland } & \text { Norway } & \text { Turkey } \\ \text { Cyprus } & \text { Ireland } & \text { Poland } & \text { Ukraine } \\ \text { Czech Republic } & \text { Italy } & \text { Portugal } & \text { UK }\end{array}$

Appendix 2: Values of the information criteria for the stochastic frontier models

\begin{tabular}{lcc}
\hline \hline \multicolumn{1}{c}{ Model } & AIC & BIC \\
\hline \hline Base non-spatial & -1323.05 & -1245.15 \\
$\mathbf{W}_{\text {All }}$ & -1467.57 & -1368.03 \\
$\mathbf{W}_{3 \text { Near }}$ & -1398.26 & -1298.72 \\
$\mathbf{W}_{4 \text { Near }}$ & -1382.03 & -1282.48 \\
$\mathbf{W}_{5 \text { Near }}$ & -1421.76 & -1322.21 \\
$\mathbf{W}_{6 \text { Near }}$ & -1479.07 & -1379.52 \\
$\mathbf{W}_{7 \text { Near }}$ & -1493.40 & -1393.86 \\
$\mathbf{W}_{3 \text { Big }}$ & -1425.49 & -1325.95 \\
$\mathbf{W}_{4 \text { Big }}$ & -1455.53 & -1355.98 \\
$\mathbf{W}_{5 \text { Big }}$ & -1483.98 & -1384.44 \\
$\mathbf{W}_{6 \text { Big }}$ & -1481.38 & -1381.84 \\
$\mathbf{W}_{7 \text { Big }}$ & -1459.40 & -1359.86 \\
\hline \hline
\end{tabular}




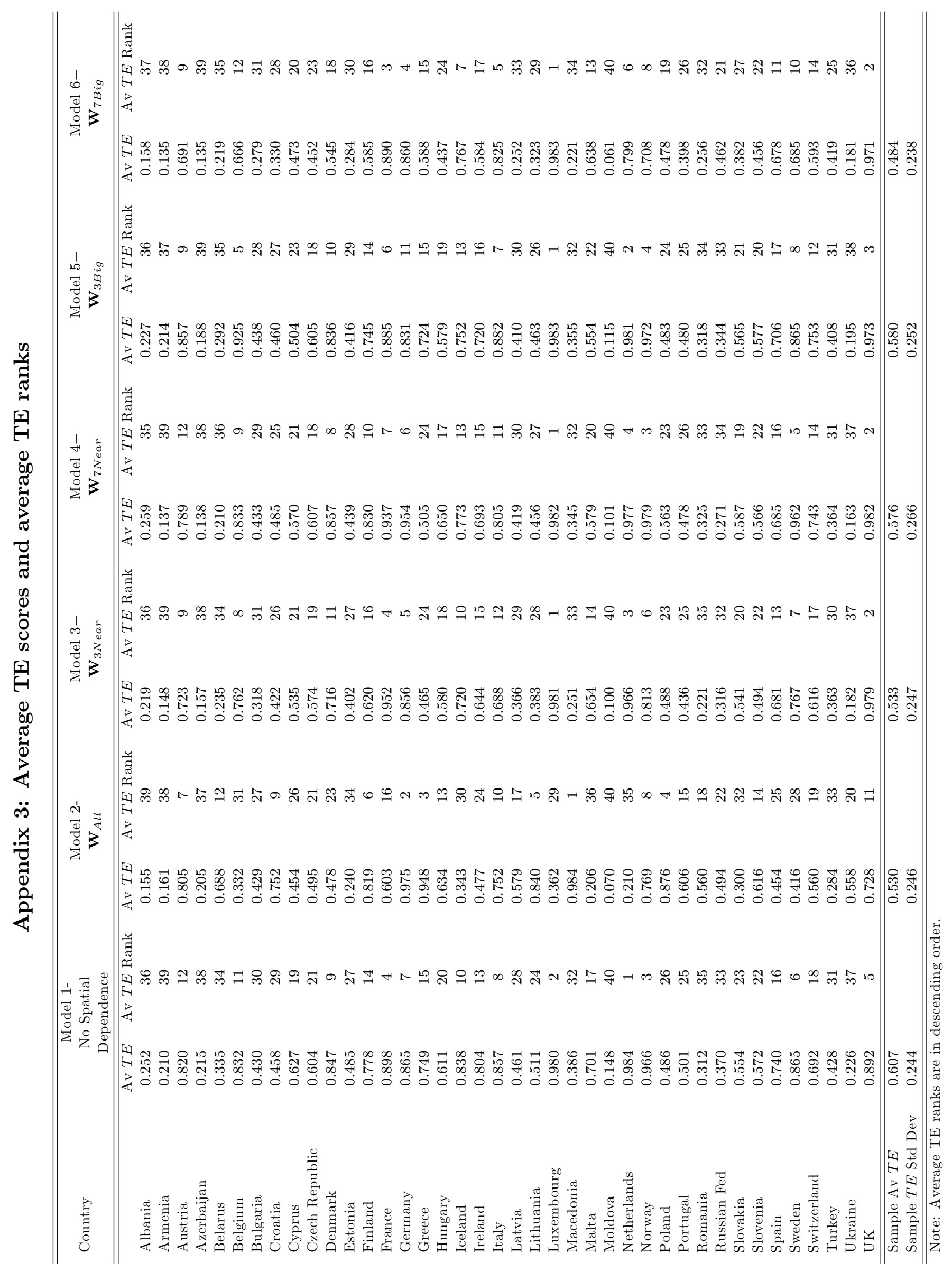

